\title{
Genetics of Acquired Antibiotic Resistance Genes in Proteus spp.
}

\author{
Delphine Girlich ${ }^{1,2,3}$, Rémy A. Bonnin ${ }^{1,2,3}$, Laurent Dortet ${ }^{1,2,3}$ and Thierry Naas ${ }^{1,2,3 *}$ \\ 1 EA7361 "Structure, dynamic, function and expression of broad spectrum $\beta$-lactamases", LabEx Lermit, Faculty \\ of Medicine, Université Paris-Saclay, Le Kremlin-Bicêtre, France, ${ }^{2}$ Associated French National Reference Center \\ for Antibiotic Resistance: Carbapenemase-producing Enterobacteriaceae, Le Kremlin-Bicêtre, France, ${ }^{3}$ Evolution \\ and Ecology of Resistance to Antibiotics Unit, Institut Pasteur - APHP - Université Paris-Saclay, Paris, France
}

\section{OPEN ACCESS}

Edited by:

Costas C. Papagiannitsis,

University of Thessaly, Greece

Reviewed by:

Jaroslav Hrabak,

Charles University, Czechia

Marco Maria D'Andrea,

University of Rome Tor Vergata, Italy

Lina Reslan,

American University of Beirut,

Lebanon

*Correspondence:

Thierry Naas

thierry.naas@aphp.fr;

thierry.naas@u-psud.fr

Specialty section:

This article was submitted to

Antimicrobials, Resistance

and Chemotherapy,

a section of the journal

Frontiers in Microbiology

Received: 26 September 2019

Accepted: 03 February 2020

Published: 21 February 2020

Citation:

Girlich D, Bonnin RA, Dortet $L$ and Naas $T$ (2020) Genetics of Acquired Antibiotic Resistance Genes in Proteus spp.

Front. Microbiol. 11:256. doi: 10.3389/fmicb.2020.00256
Proteus spp. are commensal Enterobacterales of the human digestive tract. At the same time, P. mirabilis is commonly involved in urinary tract infections (UTI). P. mirabilis is naturally resistant to several antibiotics including colistin and shows reduced susceptibility to imipenem. However higher levels of resistance to imipenem commonly occur in $P$. mirabilis isolates consecutively to the loss of porins, reduced expression of penicillin binding proteins (PBPs) PBP1a, PBP2, or acquisition of several antibiotic resistance genes, including carbapenemase genes. In addition, resistance to non$\beta$-lactams is also frequently reported including molecules used for treating UTI infections (e.g., fluoroquinolones, nitrofurans). Emergence and spread of multidrug resistant P. mirabilis isolates, including those producing ESBLs, AmpC cephalosporinases and carbapenemases, are being more and more frequently reported. This review covers Proteus spp. with a focus on the different genetic mechanisms involved in the acquisition of resistance genes to multiple antibiotic classes turning $P$. mirabilis into a dreadful pandrug resistant bacteria and resulting in difficult to treat infections.

Keywords: carbapenemase, ESBL, beta-lactamase, urinary tract infections, Proteus mirabilis

\section{INTRODUCTION}

Proteus spp. are Gram-negative rods belonging to the order of Enterobacterales and the family of Morganellaceae. These species are part of the normal bacterial flora of the intestinal tract of humans and animals, and are also widespread in the environment soil and water, where its presence is considered to result from a fecal contamination (O'Hara et al., 2000). Providencia spp., and Morganella spp., which both formerly belonged to Proteae sub-family, have been separated from the Proteus genus in 1978, and Proteus myxofaciens, never isolated from clinical samples, was proposed to be a member of a new genus, Cosenzaea gen. nov. in 2011 (Giammanco et al., 2011). On the basis of their genome-, ribosomal protein- and multi-locus sequence analysis (MLSA)based phylogenetic trees (Adeolu et al., 2016), the genera Arsenophonus, Moellerella, Morganella, Photorhabdus, Proteus, Providencia and Xenorhabdus form a distinct, monophyletic grouping, referred to as the Proteus - Xenorhabdus clade, the type genus being Morganella. All these members cluster together in a paraphyletic grouping, sharing seven conserved signature indels (CSIs) in the proteins dihydrolipoamide succinyl transferase, Xaa-Pro dipeptidase, bifunctional UDP-sugar hydrolase ( $5^{\prime}$-nucleotidase), transcriptional repair coupling factor, phosphate acetyltransferase, histidine-tRNA ligase, and $N$-acetylmuramoyl-l-alanine amidase. These bacteria are oxidasenegative, and negative for arginine decarboxylase and Voges-Proskauer. The main species of the 
Proteus genus is P. mirabilis. Proteus spp. contains six species: P. mirabilis, Proteus vulgaris, Proteus penneri, Proteus cibarius, Proteus terrae and Proteus hauseri, and three genomospecies 4, 5, and 6 (O'Hara et al., 2000). P. mirabilis, P. vulgaris, and $P$. penneri, are usually described as opportunistic pathogens with a low level of virulence (Giammanco et al., 2011). P. mirabilis is the most commonly isolated species from clinical samples, with $90 \%$ being from urinary tract infection (UTIs), but also from extra-intestinal infections such as respiratory, eye, ear, nose, skin, burn, meningoencephalitis, osteomyelitis and wound infections (Schaffer and Pearson, 2015). In 1997, P. mirabilis was the second most frequently reported enterobacterales (7.7\%) in France, after Escherichia coli (64.6\%) and before Klebsiella pneumoniae (5.9\%) (de Champs et al., 2000). In Brazil in 2011, P. mirabilis was responsible for $13.3 \%$ of the infections in intensive care units behind K. pneumoniae (56.6\%) (Abreu et al., 2011). The genome of $P$. mirabilis contains at least ten adhesion or flagella-mediated motility determinants, involved in both swimming and swarming, which is a central facet of this organism (O'Hara et al., 2000). P. mirabilis and P. vulgaris are naturally resistant to polymyxins (colistin), nitrofurans, tigecycline and tetracycline (Stock, 2003). P. vulgaris produces a chromosomally encoded inducible class A cefuroximase conferring resistance to aminopenicillins, first- and secondgeneration cephalosporins, with the exception of cefoxitin. $P$. mirabilis does not produce any chromosomally encoded $\beta$-lactamase resulting in full susceptibility to all $\beta$-lactams for a wild-type phenotype. Proteus spp. are usually susceptible to fluoroquinolones. However, strains resistant to antibiotics are increasingly reported, which complicates the treatment of infections caused by Proteus spp. Within healthcare facilities, the prevalence of amoxicillin-resistant $P$. mirabilis is close to that of E. coli (38\% to 48.5\%) (Yong et al., 2006) (Figure 1). Extendedspectrum $\beta$-lactamases (ESBLs) were first reported in 1983 (Knothe et al., 1983) and plasmid-mediated AmpC $\beta$-lactamases were reported in 1988 (Bauernfeind et al., 1989). Typically, ESBLs are mutant, plasmid-mediated $\beta$-lactamases derived from older, broad-spectrum $\beta$-lactamases (e.g., TEM-1, TEM-2, SHV-1), which have an extended substrate profile allowing hydrolysis of expanded spectrum cephalosporins, penicillins, and aztreonam. These enzymes are most commonly produced by Klebsiella spp. and E. coli but may also occur in other gram-negative bacteria, including Morganellaceae. Currently, P. mirabilis isolates have been described with multiple acquired resistance genes encoding narrow spectrum $\beta$-lactamases TEM (de Champs et al., 2000), SHV, CARB, IRT (inhibitor-resistant TEM) derivatives (Naas et al., 2003), acquired cephalosporinases [DHA (Bidet et al., 2005) CMY (Decré et al., 2002) ACC-1 (Girlich et al., 2000a)], ESBL type TEM/SHV, CTX-M, VEB (Schultz et al., 2015), PER (Nakama et al., 2016), carbapenemases (Girlich et al., 2015) (Figure 1). Epidemiological studies report a dramatic increase in ESBL producing P. mirabilis isolates. Huang et al. (2015) showed that the prevalence of ESBL-producing (mainly CTX-M14) $P$. mirabilis in Taiwan has increased approximately threefold from $6.2 \%$ in 2005 to $20 \%$ (28/140) in 2009. In India in 2011, over a 6-month period, $60 \%$ of the $P$. mirabilis collected produced an ESBL and among them $19.4 \%$ co-produced an AmpC, and 1.7\% co-produced a carbapenemase (Datta et al., 2014). A recent study on ceftriaxone non-susceptible Enterobacterales isolates in an University hospital in the United States over a 8-month period in 2015, Tamma et al. (2019) reported that (i) P. mirabilis accounted for $7.4 \%$ of the Enterobacterales with identified ESBL or AmpC and (ii) the most common ESBL in P. mirabilis were CTXM-1 group, CTX-M-9 group and SHV-type; whereas the most common AmpC was DHA-type (Tamma et al., 2019). In southern Chile at the same period, although the prevalence of CTX-M was high among Enterobacterales, $P$. mirabilis accounted only for $2.2 \%$ of them (3/137). These isolates produced simultaneously CTX-M-1-like enzymes, TEM-ESBL (3/3) and SHV-ESBL (2/3) (Pavez et al., 2019). Data from isolates recovered in 2016 and 2017 in Spain from intra-abdominal (IAI) and urinary tract (UTI) infections showed that ESBL producing Enterobacterales were mainly E. coli and K. pneumoniae. The prevalence of ESBL producing $P$. mirabilis was $0 \%$ in IAI and $1.6 \%$ in UTI in this study (Cantón et al., 2019).

Prevalence of carbapenemases in P. mirabilis is still low, nevertheless, it tends to increase over time worldwide. KPC2 carbapenemase in $P$. mirabilis was first reported in the United States in 2008 (Tibbetts et al., 2008), and then in a few studies from China 2010 (Sheng et al., 2010) and Brazil 2015 (Cabral et al., 2015). The acquisition of metallo-b-lactamase genes

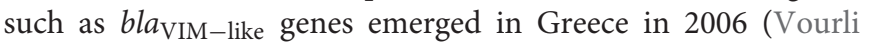
et al., 2006) in Italy in 2008 and more recently in Bulgaria (Markovska et al., 2017). IMP-producing P. mirabilis have been identified in only two studies from the United States (Dixon et al., 2016). The presence of bla $a_{\mathrm{NDM}}$ in Proteus spp. clinical isolates has been reported in few isolates but in many countries worldwide in New Zealand, in China $\left(b l a_{\mathrm{NDM}-5}\right)$, in Bulgaria (Providencia rettgeri) in 2016, in Vietnam and in France in 2012 (Girlich et al., 2015). The only descriptions of OXA-48 producing P. mirabilis isolates is from Palestine (strains isolated in 2012) (Chen et al., 2015) and from Russia (study reporting data from 2013 to 2014) (Fursova et al., 2015). Some OXA carbapenemases such as OXA-23, or OXA-58-type originating from Acinetobacter spp. are now emerging in $P$. mirabilis isolates, as we will see in the present review.

As for ESBL, ampC and carbapenemase genes, resistance genes to other antibiotic families such quinolones ( $q n r$, aac6' $\mathrm{I} b$ ) and to aminoglycosides (APH, AAC, AAD, methylases) are more and more frequently identified in $P$. mirabilis. These genes are carried on mobile genetic elements such as plasmids, transposons, mobile genomic islands, and on integrons that can be mobilized through various mobile elements.

\section{GENETIC SUPPORTS OF THE RESISTANCE IN PROTEUS SPP.}

\section{Plasmids}

Plasmids are the most frequently used vectors for the exchange of resistance genes. They are extrachromosomal, double-stranded, circular DNA molecules capable of autonomous replication and sometimes also transfer (oriT). They are host specific or broadrange. Usually, plasmids do not carry genes that are essential for 
A

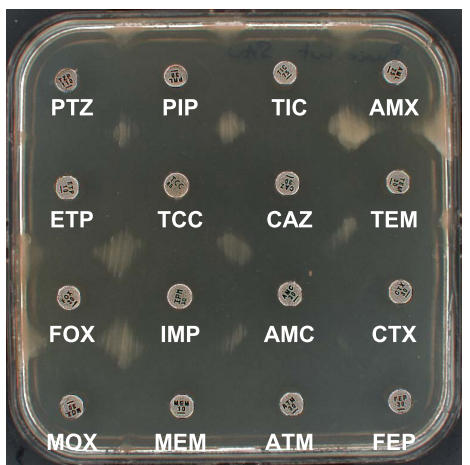

B

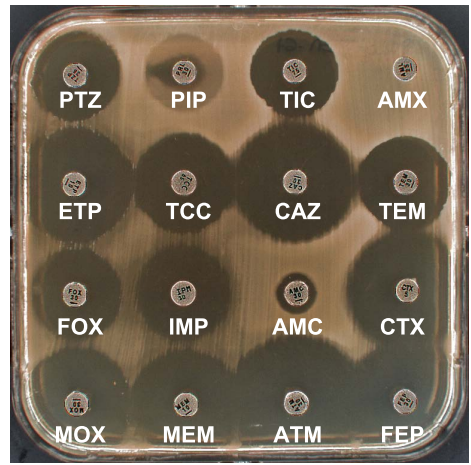

E

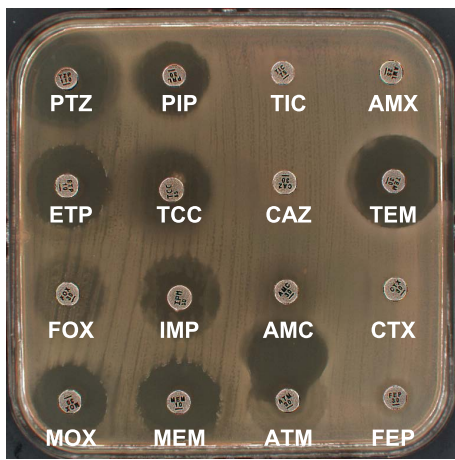

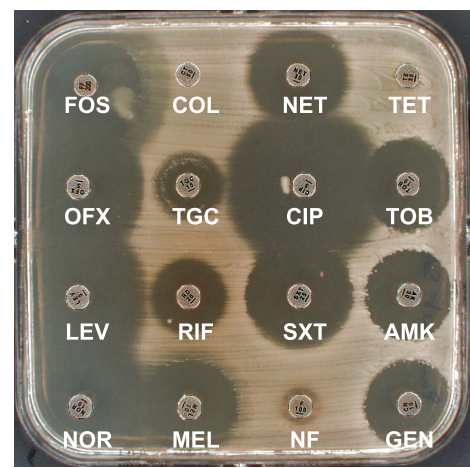

C
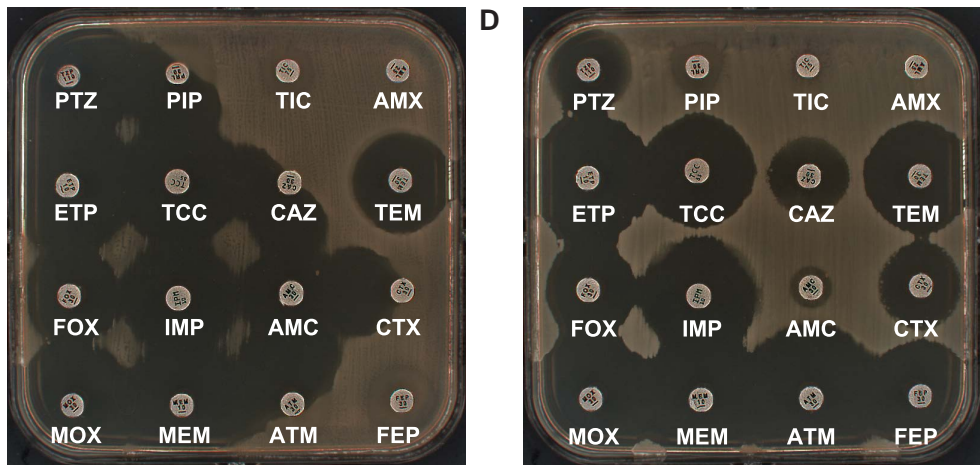

$\mathbf{F}$

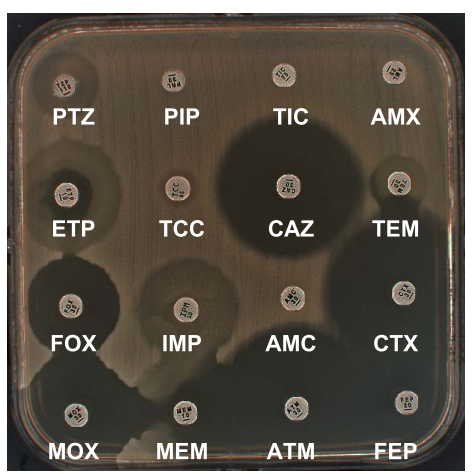

FIGURE 1 | Antibiogram of wild-type Proteus mirabilis CIP103181 (A), inhibitors resistant TEM (IRT)- TEM-67-producing P. mirabilis NEL (Naas et al., 2003) (B), ESBL producing P. mirabilis LIL-1 (Naas et al., 2000) (C), plasmid-encoded cephalosporinase ACC-1 producing P. mirabilis SPI (Girlich et al., 2000a) (D), carbapenemase NDM-1 and ESBL VEB-6 producing P. mirabilis PEL (Girlich et al., 2015) (E), Carbapenem hydrolyzing oxacillinases (CHDL) OXA-58-producing P. mirabilis 1091 (Girlich et al., 2017) (F). $\beta$-Lactam abbreviations (from left to right and top to bottom): TZP, piperacillin-tazobactam; PIP, piperacillin; TIC, ticarcillin; AMX, amoxicillin; ETP, ertapenem; TCC, ticarcillin-clavulanic acid; CAZ, ceftazidime; TEM, temocillin; FOX, cefoxitin, IMP, imipenem; AMC, amoxicillin-clavulanic acid; CTX, cefotaxime; MOX, moxalactam; MEM, meropenem; ATM, aztreonam; FEP, cefepime. Non- $\beta$-lactam abbreviations (from left to right and from top to bottom): FOS, fosfomycin; COL, colistin; NET, netilmicin; TET, tetracycline, OFX, ofloxacin; TGC, tigecycline; CIP, ciprofloxacin; TOB, tobramicine; LEV, levofloxacin; RIF, rifampicin; SXT, trimethoprim-sulfamethoxazole; AMK, amikacin; NOR, norfloxacin; MEL, Mecillinam; NF, nitrofurantoin, GEN, gentamycin.

the host survival under "non-stress" conditions and their origin of replication (ori) controls their copy number. The diversity of the ori genes is commonly used for their classification since two plasmids carrying the same replication origin cannot coexist in the same bacterium and are thus incompatible (Inc group). Carattoli (2009) have developed a molecular typing scheme using PCR amplification to discriminate the different families of plasmids circulating among Enterobacterales, such as IncHI2, HI1, I1- $\gamma, \mathrm{X}, \mathrm{L} / \mathrm{M}, \mathrm{N}, \mathrm{FIA}, \mathrm{FIB}, \mathrm{FIC}, \mathrm{W}, \mathrm{Y}, \mathrm{P}, \mathrm{A} / \mathrm{C}, \mathrm{T}, \mathrm{K}, \mathrm{B} / \mathrm{O}$. Some of these plasmid families are broad-host range (e.g., IncA/C, IncP, IncQ) that can be stably maintained in many bacterial species
(Gram+ and Gram-), while other plasmids have a narrowspectrum (e.g., IncF, IncI1) (Carattoli, 2009).

\section{Integrons}

Integrons are genetic platforms that allow the incorporation of gene cassettes such as antibiotic resistance genes encoding $\beta$-lactamases, aminoglycoside resistance determinants or plasmid-mediated quinolone resistance genes (PMQR). Integrons contain a $5^{\prime}$ conserved segment $\left(5^{\prime} \mathrm{CS}\right)$ including an integrase gene (int), a $3^{\prime} \mathrm{CS}$ comprising qacE $\Delta 1$, a defective qacE gene, encoding resistance to biocides and the sulI gene 
for resistance to sulfonamides, an attI recombination site, and $\mathrm{Pc} / \mathrm{P}_{2}$ promoters that allow the transcription of the downstream captured genes. Although integrons are not selftransferable structures, they are most often located on plasmids or transposons, allowing their efficient horizontal gene transfer (Hall and Collis, 1995). More than 130 cassettes of different genes have been identified within integrons bearing resistance to several classes of antibiotics (Partridge et al., 2009). There are complex types of integrons, which in addition to the $5^{\prime} \mathrm{CS}$ and the $3^{\prime} \mathrm{CS}$ contain the insertion sequences (ISs), ISCR1 (previously known as orf513) as explained in the following sections, and a partially duplicated 3'CS (Figures 2, 3) (Mokracka et al., 2012).

\section{Insertion Sequences and Transposons}

Bacterial insertion sequences (IS) are small DNA segments $(<2.5 \mathrm{~kb})$ with a simple genetic organization. Most IS elements exhibit short terminal inverted repeat sequences (IR) and encode a transposase, an enzyme that is required for transposition. During the process, ISs generally generate a target site duplication (TSD) (Mahillon and Chandler, 1998). These mobile elements play an important role in assembling sets of "accessory" functions in bacteria (such as genes forming parts of degradative or catabolic pathways) and in dissemination of resistance genes. By inserting within a coding-sequence they may inactivate the gene, or by inserting upstream of a gene they may modify its expression. ISs may also help integration of plasmids into the chromosome of bacteria.

Transposons are mobile elements capable of mobilizing foreign DNA through a transposition process. Two main classes of transposons are involved in acquisition of resistance genes:

- Class 1 transposons or composite transposons are made of 2 copies of identical or almost identical ISs that may mobilize the DNA sequence located between them. A known example of this kind of transposon is Tn1999, an IS1999-composite transposon at the origin of mobilization of bla $a_{\text {OXA }-48}$ carbapenemase gene from the chromosome of Shewanella spp. to an IncL plasmid (Poirel et al., 2012).

- Class 2 transposons or non-composite transposons are made of two IR sequences that surround a transposase gene, transposition accessory genes (such as a replicase, transposition regulatory genes, ...) and genes that most often encode resistance determinants. This allows the transposition of the carried DNA with great efficiency. The most widespread $\beta$-lactamase, bla $a_{\mathrm{TEM}-1}$ is carried by a class 2 transposon, Tn3 (Bailey et al., 2011). The association of integrons with these transferable elements may promote rapid dissemination of antibiotic resistance genes among clinical strains and create further opportunities for inclusion of additional genes within mobile elements.

\section{Peculiar Insertion Sequences: ISEcp1 and ISCR1}

The mobilization of ESBLs, AmpCs and carbapenemase genes and their exchange between Enterobacterales species and Enterobacterales and non-fermenters may take place using peculiar ISs, such as ISEcp1 and ISCR1. They are capable of mobilizing nearby DNA, by a mechanism similar to oneended-transposition. ISEcp 1 preferentially recognizes flanking sequences as an inverted repeat, rather than its own right IR and thus is capable of mobilizing foreign DNA that is located nearby the right IR (Tamma et al., 2019). Gene mobilization may also take place by "rolling circle" replication via specific IS named ISCR1- type (or orf513) elements. In P. mirabilis these types of elements have been described for bla $a_{\mathrm{CTX}-\mathrm{M}-}$, plasmid encoded $b l a_{\mathrm{ampC}}$, and the $b l a_{\mathrm{NDM}-1}$ carbapenemase genes in particular (Qin et al., 2015) (Figures 2, 3). The mechanism of mobilization of resistance genes through a rolling circle transposition/recombination process is still not fully understood.

\section{Integrative Conjugative Elements (ICEs)}

Integrative conjugative elements are auto-transferable mobile genetic elements that can be excised from the chromosome via their integrase/excisionase gene of the host bacterium and form a circular intermediate that can be transferred by conjugation (Li et al., 2016). The ICE SXT/R391 family is one of the largest ICE families with the most abundant diversity among Gramnegative bacterial species. They carry genes coding for the resistance to sulfamethoxazole, trimethoprim, chloramphenicol, mercury, streptomycin and kanamycin, as well as $\beta$-lactamases genes [bla $a_{\mathrm{HMS}-1}$ (Ryan et al., 2017), bla $a_{\mathrm{CMY}-2}$ (Harada et al., 2010), bla $a_{\mathrm{CTX}-\mathrm{M}-2}$ (Mata et al., 2011)]. SXT/R391-type ICEs have been identified in strains of $P$. mirabilis not only in Asia (Li et al., 2016) but also in Spain (Mata et al., 2011) and in France (Aberkane et al., 2016). They are easily transferable by conjugation of $P$. mirabilis to E. coli, K. pneumoniae, Salmonella enterica serovar Typhimurium, or Citrobacter koseri (Harada et al., 2010) (Figures 2, 3).

Among ICEs, a specific genomic island described in Salmonella, named SGI for Salmonella Genomic island (Doublet et al., 2005) have been described in Proteus spp. They are integrative elements that can be mobilized by auxiliary plasmids and are classified as IME for Integrative and Mobilizable Elements.

The first SGI1 in $P$. mirabilis was detected from a Palestinian patient in 2006 (Ahmed et al., 2007). It contained genetic determinants conferring resistance to ampicillin, chloramphenicol, streptomycin, sulfonamides, trimethoprim, nalidixic acid and tetracycline. Since then, multiple SGI1 variants have been described in Salmonella and are classified from SGI1-A to SGI1-Y, depending on the variable part of their multiresistance region. Several variants of SGI1, such as SGI1-L and SGI1-U to SGI1-Y have also been described in some $P$. mirabilis isolates (Girlich et al., 2015). Some of these SGIs, integrated in the chromosome of $P$. mirabilis, have recently been renamed PGI (for "Proteus Genomic Island") (Girlich et al., 2015). These pathogenicity islands (PAIs) may also contain multiple $\beta$-lactamase-encoding genes, including bla $a_{\mathrm{VEB}-6}$ (Girlich et al., 2015) and bla $a_{\mathrm{NDM}-1}$ (Girlich et al., 2015) (Figures 2, 3). Most of these PAIs have lost their horizontal transfer capacity (Schmidt and Hensel, 2004). In P. mirabilis, the integration of SGI1/PGI1 into the chromosome always takes place in the $3^{\prime}$ end of the thdF gene, encoding a protein involved in oxidation reactions and induced during the stationary phase (Zabel et al., 2000). 
A

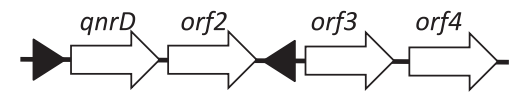

B

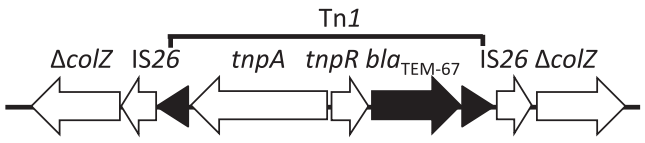

C

$\operatorname{Tn} 6093$

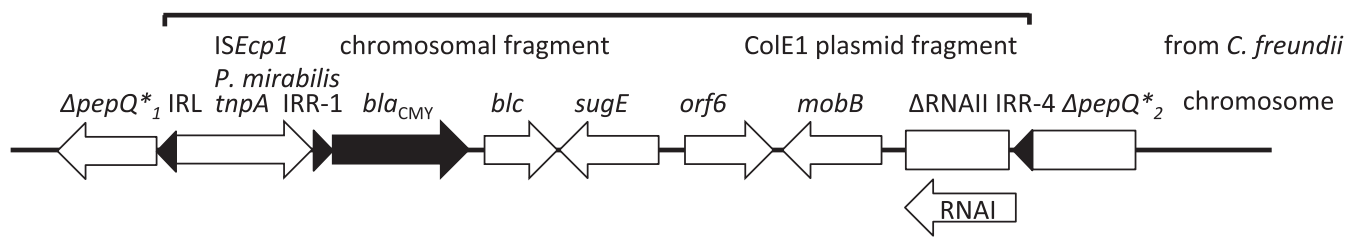

D

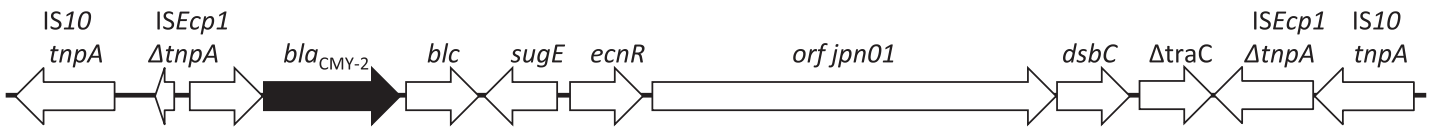

E

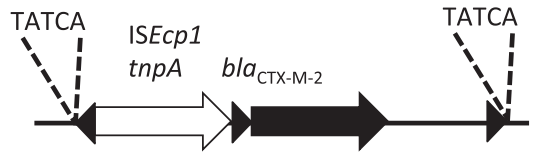

FIGURE 2 | Schematic representation of the structure containing (A) the qnrD gene in P. rettgeri pDIJ09-518a on a non-transmissible plasmid, the right (IRR) and left $(\mathrm{RL})$ repeated inverted sequences also named "mobile insertion cassette" elements (mic), used for mobilization of qnrD, are indicated by black triangles (Guillard et al., 2014); (B) the blaTEM-67 gene in Tn1 flanked by two IS26 on the non-transferable plasmid of P. mirabilis NEL (Naas et al., 2003); (C) the bla $\mathrm{CMY}$ gene within the ISEcp1: Tn6093 transposition module inserted into the pepQ gene of P. mirabilis (D'Andrea et al., 2006); (D) the blacmY-2 gene inserted into ICE R391 from P. mirabilis PmiJpn1 (Harada et al., 2010); (E) the blacTX-M-2 gene located on the chromosomes of P. mirabilis TUM4657 (Harada et al., 2012 ), the 5 letters correspond to the direct repeat sequences (DRL and DRR). The $\beta$-lactamase genes and their orientation are represented by black arrows and the IS by black triangles, including the IR-R and IR-L of ISECP1 and the IR-R of the ISECP1 transposition unit.

The strains of $P$. mirabilis carrying these islands have now disseminated also in animals (Schultz et al., 2015).

\section{RESISTANCE TO AMINOGLYCOSIDES IN PROTEUS SPP.}

In P. mirabilis, genetic determinants involved in aminoglycosides resistance are mostly located on integrons as gene cassettes. Most often, these genes are aadA1, aadA2, coding for aminoglycoside adenyltransferases; $a a d B$, coding for aminoglycoside $\left(2^{\prime \prime}\right)$ transferase; $a a c\left(6^{\prime}\right)-I b$ (also named aacA4), coding for an aminoglycoside acetyltransferase; and sat2, coding for a streptothricin acetyltransferase (Mokracka et al., 2012). The plasmid-mediated 16S rRNA methylase RmtA was initially characterized in a clinically isolate of Pseudomonas aeruginosa (Yokoyama et al., 2003). Then several variants (RmtA, B, C, $\mathrm{D}$ and ArmA) have been found in Enterobacterales including P. mirabilis (Wachino et al., 2006; Galani et al., 2012; Leulmi et al., 2019). The presence of such determinants on acquired genetic structures also carrying other resistance genes such as the $b l a_{\mathrm{NDM}}$ gene on the plasmid from K. pneumoniae Saitama (GenBank AB759690) constitute a risk of co-selection. The acceleration of aminoglycoside resistance among gram-negative bacilli due to plasmid-mediated 16S rRNA methylases, may indeed become an actual clinical hazard in the near future, as the bacteria become resistant to all aminoglycosides.

\section{RESISTANCE TO QUINOLONES IN PROTEUS SPP.}

It is common to observe in fluoroquinolone-resistant mutants substitutions in the genes encoding chromosomal DNA gyrase ( gyrA and gyrB) or topoisomerase IV (parC and parE) (Cambau et al., 2006). The rate of resistance related to chromosomal mutations in the fluoroquinolones' targets was around $70 \%$ in Gram-negative enteric isolates in a study by Ogbolu et al. (2011) in Nigeria in 2010. Resistance to quinolones is also mediated by three mechanisms of plasmid resistance: protection of the quinolone target (DNA gyrase and topoisomerase IV) by proteins encoded by the $q n r$ genes, acetylation of ciprofloxacin and 


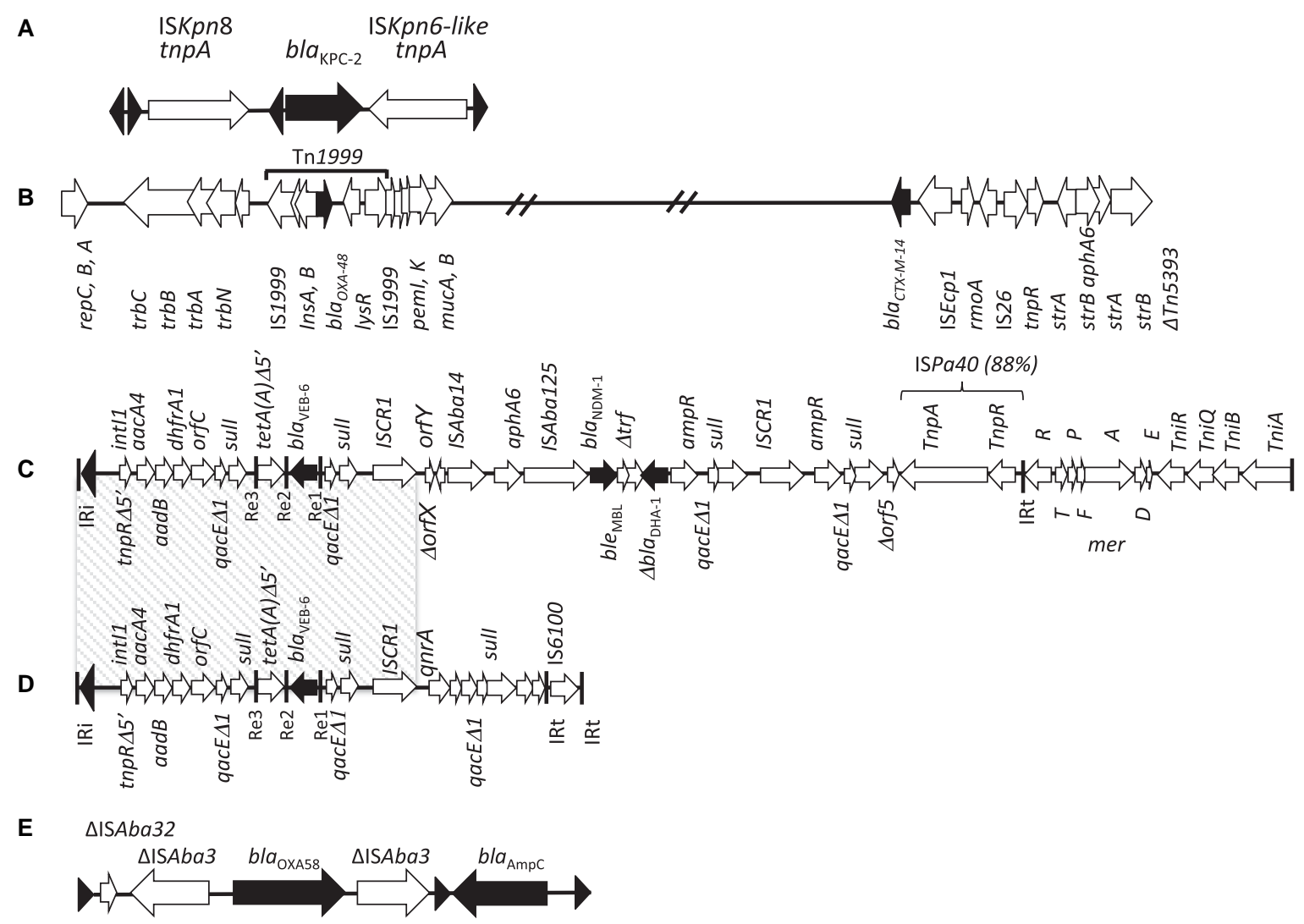

FIGURE 3 | Genetic environments of $\beta$-lactamase genes identified in P. mirabilis. (A) Fragment 3,241 pb from P. mirabilis, China, 2015 (Hu et al., 2012 ), containing blaKPC-2, ISKpn8 and ISKpn6-like, chimera of several elements of transposons Tn4401 and Tn3, as described for K. pneumoniae KP048 (Shen et al., 2009 ); (B) plasmid fragment from OXA-48 and CTX-M-14 -producing P. mirabilis, Gaza, Palestine (Chen et al., 2015); (C) PGl1-PmPEL genomic island, France, 2016 (Girlich et al., 2015), with the multidrug resistance region (MDR) containing the bla $\mathrm{NDM}_{-1}$ and blaVEB-6 (D) genes and comparison with SGl1-V from P. mirabilis, France, 2009 (Siebor and Neuwirth, 2011), containing a 17,1 kb MDR on a complex class 1 integron, including blaveB-6, aacA4, aadB and dhfrA1 genes bracketed by two $3^{\prime}$ conserved segments (3'-CS); (E) chromosomal fragment from P. mirabilis 1091 isolate, Belgium, 2017 (Girlich et al., 2017), containing blaoxA-58 [from

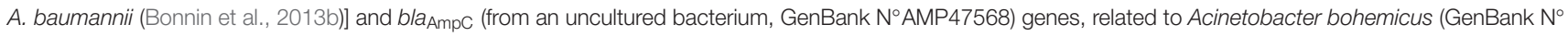
WP_004650432). Triangles represent tandem repeats of 14-pb. The $\beta$-lactamase genes and their orientation are represented by black arrows and ISs by black triangles.

norfloxacin by the enzyme $\mathrm{AAC}\left(6^{\prime}\right)$-Ib-cr and quinolones specific (QepA) or non-specific (OqxAB) efflux pumps (Zhang et al., 2013). Resistance to quinolones, mediated by aac $\left(6^{\prime}\right)$-Ib-cr and $q n r$ was the most frequent, and was observed in 17.2 and $8.2 \%$ respectively of the quinolone-resistant strains in the Ogbolu et al. (2011) study, while qepA was detected only in $3.2 \%$ of these strains. In 2017, this rate was significantly higher in Nigeria where $q n r A$ and $a a c\left(6^{\prime}\right)-I b$-cr were detected in, respectively, 36.7 and 5\% of the 108 multidrug resistant $P$. mirabilis tested. These genes were most often carried associated with $\beta$-lactamase genes (bla $a_{\text {TEM }}$ or bla $a_{\text {CTX-M }}$ ) on class 1 and class 2 integrons (Alabi et al., 2017). It was observed that the qnrB10 and $a a c\left(6^{\prime}\right)-I b-c r$ genes were significantly associated with the ESBL genes whereas this is not the case for the qnrB19 nor qnrD (Albornoz et al., 2014).

Since, most of the reported qnrD-positive isolates belong to Proteus or Providencia genera, Guillard et al. (2014) hypothesized that $q n r D$ originated in Morganellaceae before disseminating to other species of Enterobacterales. In these two genera the qnrD gene is located on small, non-conjugative $2.7 \mathrm{~kb}$ plasmids and $\sim 4.2 \mathrm{~kb}$ mobilizable by "mobile insertion cassette" elements (mic) (Guillard et al., 2014) (Figure 2). The mic elements are delineated by two IR sequences without transposase gene and a target duplication site, signatures of transposition events (Guillard et al., 2014). Proteus spp. harboring plasmids with the qnrD genes disseminate worldwide such as, in China (Zhang et al., 2013), Argentina (2014) (Albornoz et al., 2014), Nigeria (Ogbolu et al., 2011), Italy (Mazzariol et al., 2012), France (Guillard et al., 2014) and Poland with P. vulgaris (Mokracka et al., 2012). The qnrC gene was described in 2009 in China in a strain of P. mirabilis and confers only a decrease in susceptibility to ciprofloxacin and levofloxacin. It was located on a $120-\mathrm{kb}$ plasmid co-harboring resistance determinants to ampicillin, sulfamethoxazole, and trimethoprim (Wang et al., 2009). The qnrA (Ogbolu et al., 2011) and qnrS (Mokracka et al., 2012) genes have been more rarely described in Proteus spp. isolates. The qnrA genes could have for progenitor an environmental species, Shewanella algae (Poirel et al., 2005). In France, it seems that the qnrA-containing strains are most often SHV-12 producing Enterobacter cloacae and the 
presence of these genes would be related to the dissemination of an integron of the In36-like type (Cambau et al., 2006). In $P$. mirabilis, the presence of $q n r A$ remains extremely rare. Only one qnrA-producing isolate has been recovered among 1,468 Enterobacterales collected in patients hospitalized in France from 2002 to 2005 (19 P. mirabilis in total). This P. mirabilis isolate also produced the ESBL PER-1 (Cambau et al., 2006). The qnrA gene was located on a 20 to $100 \mathrm{~kb}$ plasmid, downstream of ISCR 1 and upstream of $a m p R$ (encoding the repressor of the $a m p C$ gene) and qacE $\Delta 1$ (a partially deleted gene that would be involved in the resistance to quaternary ammonium compounds). In another strain of $P$. mirabilis isolated in France in 2009, qnrA was located on the same genomic island as the bla $a_{\mathrm{VEB}-6}$ gene (SGI1-V) (Figure 2) (Siebor and Neuwirth, 2011). More recently, the qnrA gene was identified as chromosomally encoded surrounded by IS10 and two copies of ISCR1 in an environmental strain of P. mirabilis (Jayol et al., 2016).

\section{RESISTANCE TO $\beta$-LACTAMS IN PROTEUS SPP.}

Ceftazidime, piperacillin-tazobactam, and meropenem are most efficient molecules against $P$. mirabilis, inhibiting $>98.0 \%$ of the clinical strains from US hospitals from 2011 to 2013 (Castanheira et al., 2015). However, nearly all the $\beta$-lactamases arsenal that has been reported in Enterobacterales has also be described in Proteus spp. These $\beta$-lactamases ranged from (i) narrowspectrum $\beta$-lactamases with a penicillinase phenotype to (ii) ESBL and acquired AmpCs able to hydrolyze nearly all $\beta$-lactams except carbapenems, and finally (iii) carbapenemases of various molecular classes.

\section{Narrow-Spectrum $\beta$-lactamases in Proteus spp.}

Narrow-spectrum $\beta$-lactamases being inhibited by clavulanic acid (e.g., TEM-1 and TEM-2; SHV-1) or being resistant to the action of clavulanic acid (e.g., IRT, OXAs) have been reported in Proteus spp. These enzymes hydrolyze narrow-spectrum penicillins, slightly 1st generation cephalosporines (GC) but are not active on 2nd and 3rd GC and carbapenems.

\section{TEM-Type}

TEM-1 was the first plasmid-mediated penicillinase $\beta$-lactamase, described in the 1960s in Gram-negative bacteria. It belongs to the class A or the Ambler classification (Ambler, 1980) and to the group 2b of Bush and Jacoby one (Bush and Jacoby, 2010). Its hydrolytic profile includes penicillins and first-generation cephalosporins (cephalothin). This enzyme is well inhibited by clavulanic acid and tazobactam (Table 1). In P. mirabilis, a wide variety of TEM variants have been described including the penicillinases TEM-1 and TEM-2 (Pagani et al., 2003), some TEM resistant to $\beta$-lactamase inhibitors such as clavulanic acid, sulbactam and tazobactam [IRT, group 2br (Bush and Jacoby, 2010) including TEM-65, TEM-67, TEM-73, and TEM74] (de Champs et al., 2000), and finally extended-spectrum TEM enzymes [ESBL, 2be group (Bush and Jacoby, 2010)].
Overall, TEM-1 is the most commonly described enzyme in penicillinase-producing $P$. mirabilis strains. In $P$. mirabilis, IRT enzymes are TEM-2 derivatives, with a cysteine/serine replacing arginine 244 (IRT-1/IRT-2-like). IRT-2 in P. mirabilis confers a high level of resistance to amoxicillin and amoxicillin-clavulanate combination but a low level of resistance to ticarcillin (Bret et al., 1996). IRT-2-producing $P$. mirabilis remains susceptible to the combination ticarcillin-clavulanate, piperacillin and cephalothin (Table 1) (Bret et al., 1996). In the study of Bret et al. (1996) the $b l a_{\mathrm{IRT}-2}$ gene was carried by a conjugative plasmid. In the P. mirabilis strain producing the IRT-1 derivative, TEM-67, the gene was carried by a $48-\mathrm{kb}$ non-self-transferable plasmid within a Tn1-like transposon (Naas et al., 2003) (Figure 2 and Table 1).

\section{HMS-1}

HMS- 1 is a $\beta$-lactamase that was characterized as IRT in a strain of P. mirabilis in 1990 by Thomson et al. (1990). It confers resistance to ticarcillin-clavulanate and a reduced susceptibility to the cefoperazone-sulbactam combination (Thomson et al., 1990). The bla $a_{\mathrm{HMS}-1}$ gene, located on a SXT/R391 island, has recently been identified by Li et al. (2016) in P. mirabilis strains collected from rectal swabs of diarrheal patients and in food (raw meat) from 2008 to 2015 in three cities in China.

\section{SHV-Type}

SHV-1 is the natural $\beta$-lactamase of $K$. pneumoniae, which makes this species also the most prevalent producer of ESBL of SHVtype through point mutation in the active site of this enzyme (Perilli et al., 2002). Few SHV-producing P. mirabilis isolates have been reported. They either produce the SHV-1 penicillinase (Chanal et al., 2000) or the SHV-5 ESBL (Ho et al., 2005).

\section{CARB/RTG Enzymes}

Carbenicillinases of the CARB group were initially reported from $P$. aeruginosa (Labia et al., 1981) then in several species such as Acinetobacter calcoaceticus (Choury et al., 2000), Vibrio cholerae (Choury et al., 1999) and P. mirabilis [RTG-1 (Takahashi et al., 1983), CARB-2/PSE-1 (Chanal et al., 2000)]. These plasmidencoded enzymes belong to the functional group $2 \mathrm{c}$ as they hydrolyze benzylpenicillin, ampicillin, and carbenicillin (Bush and Jacoby, 2010). They are mostly of restricted-spectrum and of low prevalence, especially in Enterobacterales.

\section{Narrow Spectrum Oxacillinases}

Oxacillinases are enzymes that hydrolyze preferentially cloxacillin and oxacillin and are not or very poorly inhibited by clavulanic acid or tazobactam. In P. mirabilis clinical isolates the most prevalent narrow-spectrum oxacillinases are OXA-1, OXA-9, OXA-10 and some point mutant derivatives, such as OXA-320, an OXA-1 single amino-acid mutant that has exclusively been found in $P$. mirabilis from Turkey so far (Cicek et al., 2014). These genes are integron-borne, and thus generally associated with other resistance genes (aminoglycosides, tetracycline, chloramphenicol, etc...), including ESBLs genes such as bla $a_{\mathrm{VEB}-1}$ (Naas et al., 2000; Kim et al., 2004) even simultaneously associated with carbapenemases genes such as

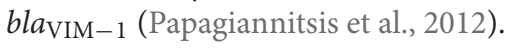


TABLE 1 | Minimal Inhibitory Concentrations (MIC) of $\beta$-lactams in P. mirabilis of wild type or $\beta$-lactamases producing isolates ${ }^{\mathrm{a}}$

\begin{tabular}{|c|c|c|c|c|c|c|c|c|c|c|c|c|c|c|}
\hline \multirow[b]{3}{*}{ b-lactam } & \multicolumn{14}{|c|}{ MIC (mg/L) } \\
\hline & \multirow[t]{2}{*}{ Wild type } & \multirow{2}{*}{$\begin{array}{c}\text { Penicillinase } \\
\text { TEM-1 }\end{array}$} & \multirow{2}{*}{$\begin{array}{c}\text { IRT }^{\mathrm{b}} \\
\text { TEM-67 }\end{array}$} & \multicolumn{3}{|c|}{ ESBL } & \multicolumn{3}{|c|}{ Cephalosporinase } & \multicolumn{5}{|c|}{ Carbapenemase } \\
\hline & & & & TEM-3 & TEM-52 & CTX-M-2 & CMY-2 & CMY-3 + TEM-2 & ACC-1 & KPC-2 & NDM-1 + VEB-6 & OXA-48 + CTX-M-14 + TEM-1 & OXA-23 & OXA-58 \\
\hline $\mathrm{AML}^{\mathrm{b}}$ & 1 & 512 & $>512$ & $>512$ & $>512$ & $>512$ & $>512$ & $>512$ & $>512$ & $>512$ & $>256$ & & 256 & $>512$ \\
\hline AMC & 0.5 & 4 & 256 & $4-16$ & 1 & & $>512$ & $>512$ & & $>512$ & 64 & & 256 & $>512$ \\
\hline $\mathrm{TIC}$ & 0.5 & 128 & 8 & $>512$ & $>512$ & & & $>512$ & 512 & & 256 & $>128$ & 64 & $>512$ \\
\hline TCC & 0.5 & 2 & 4 & $8-16$ & & & & 128 & 4 & & 32 & $>2$ & 64 & $>512$ \\
\hline PRL & 8 & 8 & 4 & $32-256$ & $>512$ & $>512$ & $>512$ & & 128 & & 12 & & 16 & $>512$ \\
\hline TZP & 8 & 0.5 & & $1-2$ & 0.5 & 0.25 & 16 & & 8 & 32 & 12 & & 0.5 & $>512$ \\
\hline CF & & 8 & 16 & 32 & & $>512$ & & $>512$ & $>512$ & & & & 4 & ND \\
\hline FOX & & & & & 2 & 0.5 & 128 & & 4 & 16 & & & 2 & \\
\hline CAZ & 0.06 & & 0.5 & $1-2$ & 32 & 0.25 & 16 & 128 & 64 & 16 & $>256$ & & 0.06 & 0.05 \\
\hline CTX & 0.03 & & & $2-8$ & 16 & $>512$ & 8 & 256 & & 8 & $>256$ & $>32$ & 0.06 & 0.03 \\
\hline FEP & ND & & & & 64 & $>512$ & 2 & & 0.25 & $>16$ & 64 & $>16$ & & 0.09 \\
\hline IPM & 0.75 & & & $0.5-8$ & 4 & 0.12 & 8 & 4 & 0.25 & 8 & 32 & $>8$ & $0.25-0.5$ & 0.75 \\
\hline ETP & 0.06 & & & & 0.01 & & & & & $0.25-4$ & 0.25 & & & 0.12 \\
\hline MEM & ND & & & & 0.25 & & & & & $1-2$ & 0.75 & & $2-4$ & 0.06 \\
\hline DOR & & & & & & & & & & & & 2 & & \\
\hline ATM & $<0.03$ & & & $0.12-0.5$ & 0.5 & 32 & & 4 & 0.25 & & 8 & & 0.06 & $<0.03$ \\
\hline TEM & 1.5 & & & & & & & & & & & & & 128 \\
\hline
\end{tabular}

aWild type P. mirabilis CIP103181 (Girlich et al., 2017), restricted-spectrum penicillinase TEM-1 in P. mirabilis CF19 (de Champs et al., 2000); extended-spectrum $\beta$-lactamase (BLSE) TEM-3 in P. mirabilis PSM1-5 (Mariotte et al., 1994); TEM-52 in P. mirabilis DG6499 (Tonkic et al., 2010) and P. mirabilis PM685 (Luzzaro et al., 2001); CTX-M-2 in P. mirabilis TUM4653 (Harada et al., 2012 ) and P. mirabilis PM15SM02 (Pagani et al., 2003); IRT (TEM-67) in P. mirabilis NEL (Naas et al., 2003); plasmid-encoded cephalosporinase CMY-2 in P. mirabilis TUM4660 (Harada et al., 2010$)$, CMY-3 (+TEM-2) in P. mirabilis CF09 (Bret et al., 1998) and ACC-1 in P. mirabilis SPI-1 (Girlich et al., 2000a); carbapenemases KPC-2 in P. mirabilis from China (Hu et al., 2012) and Brazil (Cabral et al., 2015); NDM-1 (+VEB-6) in P. mirabilis PEL (Girlich et al., 2015), OXA-48 (+CTX-M-14 + TEM-1) in P. mirabilis Pm-OXA-48 (Chen et al., 2015); OXA-23 in P. mirabilis CF0239 (Bonnet et al., 2002) and OXA-58 in P. mirabilis 1091(Girllich et al., 2017). b/RT, Inhibitor-Resistant TEM $\beta$-lactamase; AML, amoxicillin; AMC, amoxicillin-clavulanate; ATM, aztreonam; CAZ, ceftazidime; CF, cephalothin; CTX, cefotaxime; DOR, doripenem; ETP, ertapenem; FEP, cefepime; FOX, cefoxitin; IPM, imipenem; MEM, meropenem; PRL, piperacillin; TEM, temocillin; TCC, ticarcillin-clavulanate; TIC, ticarcillin; TZP, piperacillin-tazobactam. 
Other ESBLs such as CTX-M-15, SHV-12, TEM-28 or carbapenemases such as NDM-1 have also been described in P. mirabilis (Dortet et al., 2012).

\section{Extended-Spectrum $\beta$-Lactamases (ESBLs) in Proteus spp.}

Although the first reported ESBL were of TEM-type, a diversification of these ESBLs occurred in 2000s with the emergence of CTX-M enzymes, as concomitantly observed in other species of Enterobacterales such as E. coli and K. pneumoniae. CTX-M enzymes may be divided in five distinct groups of enzymes based on their primary amino acid sequence (Group 1, 2, 8, 9, and 25). Usually, ESBL production provides a high level of resistance to ceftazidime, cefotaxime and aztreonam in Proteus spp. The first ESBL-producing P. mirabilis isolate has been described in France in 1999 (de Champs et al., 2000). The prevalence of ESBL-producing Proteus spp. is 1.3\% in Spain, $3.3 \%$ in France, $5.9 \%$ in Greece (Tonkic et al., 2010), 12.6\% in Croatia, $14.5 \%$ in Poland and $16.3 \%$ in Italy (Nijssen et al., 2004). In Hong Kong, for example, the emergence of ESBLproducing $P$. mirabilis strains was monitored in a hospital by Ho et al. (2005) from 1999 to 2002, when the proportion of ESBLproducing $P$. mirabilis increased from $0 \%$ in 1999 to $18.5 \%$ in 2001 and $25.8 \%$ in 2002 (8/31 strains of $P$. mirabilis isolates). The ESBL content of these isolates was more diverse, with CTXM-13, CTX-M-14, SHV-5 and TEM-11 (Ho et al., 2005). The emergence of CTX-M enzymes was also reported in Japan with CTX-M-2 and CTX-M-10 (Nagano et al., 2003). Jones et al. (2009) reported a prevalence of 7\% of ESBL-producers among P. mirabilis in Eastern Europe, 10\% in Latin America, and 2.2\% in North America. In 2013, in a large study including 8,800 isolates of Enterobacterales from the USA, the proportion of ESBLproducers was of $8.4 \%$. In this study, although ESBL-producers were mostly found in E. coli (49.5\%) and K. pneumoniae (40.1\%), they represented $5.2 \%$ of $P$. mirabilis isolates (Castanheira et al., 2015). In this large collection, Group 1 and Group 9 CTX-Ms were predominant. More sporadically, other rare ESBLs such as PER-1 (Pagani et al., 2003), and VEB (Siebor and Neuwirth, 2011) were detected in P. mirabilis. Tonkic et al. (2010) observed that ESBL-producing Enterobacterales were generally susceptible to carbapenems, cefoxitin and to $\beta$-lactamase inhibitors, but resistant to most non- $\beta$-lactam antibiotic molecules such as ciprofloxacin, trimethoprim/sulfametoxazole, gentamicin, netilmicin, and amikacin. Accordingly, the emergence of $P$. mirabilis strains accumulating resistance mechanisms such as resistance to aminoglycosides (aacA4, aadB, aphA6), expandedspectrum $\beta$-lactams $\left(b l a_{\mathrm{VEB}-6}\right)$ and carbapenems $\left(b l a_{\mathrm{NDM}-1}\right)$ (Girlich et al., 2015) are increasingly reported (Figure 1 and Table 1).

\section{TEM-Type and SHV-Type ESBLs}

TEM-type ESBLs were identified for the first time in $P$. mirabilis by Mariotte et al. (1994). The bla $a_{\mathrm{TEM}-3}$ gene was located on a conjugative plasmid of 47-kb (Mariotte et al., 1994). In a French study on $>3,000 P$. mirabilis strains collected between 1997 and 2002, the prevalence of ESBL-producers was 1.3\%, all of TEM-type (TEM-24, TEM-52, et TEM-92) (Biendo et al., 2005).
Whereas in 2002 in Italy the proportion of strains of ESBLproducing $P$. mirabilis among $P$. mirabilis isolates was $16.3 \%(98 \%$ TEM type), compared with $28.1 \%$ for Providencia stuartii, $20 \%$ for K. pneumoniae, and 1.2\% for E. coli (Spanu et al., 2002).

Several TEM ESBL variants have been identified in P. mirabilis, TEM-11 in Hong Kong (Ho et al., 2005), TEM-21 in France (Arpin et al., 2003), TEM-15, -20, -72, -87 in Italy (Perilli et al., 2002), TEM-155 in the US (Perilli et al., 2002). Overall the most prevalent TEM-type ESBL is TEM-52 (Sardelić et al., 2010). In Croatia, the prevalence of ESBL-producing $P$. mirabilis isolates increased from $0.5 \%$ in 2005 to $20.9 \%$ in 2008 , and this ESBL was systematically TEM-52 (Hu et al., 2012). TEM-52-producing P. mirabilis strains are susceptible or of reduced susceptibility to cefotaxime and cefepime and are always susceptible to ceftazidime and aztreonam (Pagani et al., 2003) (Table 1). It has been observed that diffusion of TEM-52 producing isolates may be due to the massive use of cefotaxime and moxalactam (Perilli et al., 2002). The bla $a_{\mathrm{TEM}-52}$ gene is located either on the chromosomal (Tonkic et al., 2010), or on plasmids (Sardelić et al., 2010) whereas bla $a_{\mathrm{TEM}-3}, b l a_{\mathrm{TEM}-24}$, and bla $a_{\mathrm{TEM}-66}$ are carried by large plasmids (de Champs et al., 2000). In 2002-2006, TEMtype ESBLs were supplanted by CTX-Ms in 85,71 , and $43 \%$ of E. coli, K. pneumoniae, and P. mirabilis positive ESBL strains, respectively (Jones et al., 2009).

As previously mentioned, only few SHV-producing P. mirabilis isolates have been reported. Only the SHV-5 ESBL has been described in P. mirabilis (Abreu et al., 2011).

\section{CTX-Ms}

Other class A enzymes with an extended spectrum, CTX-M enzymes are non-TEM, non-SHV ESBLs formerly known as FEC-1 (Matsumoto et al., 1988). Initially reported in the second half of the 1980s, their rate of dissemination has largely increased since 1995 (Bonnet, 2004). The hydrolytic profile includes aminopenicillins (ampicillin, amoxicillin), carboxypenicillins (carbenicillin, ticarcillin), ureidopenicillins (piperacillin), and narrow-spectrum cephalosporins (cephalothin, cephaloridine, cefuroxime), but cefoxitin and carbapenems are spared (Table 1). CTX-M-1 has been initially characterized by a better hydrolysis of cefotaxime than ceftazidime (Bauernfeind et al., 1996a). Currently, there are more than 150 allelic variants of CTX-Ms. These enzymes are classified into five major phylogenic groups: CTX-M-1, CTX-M-2, CTX-M-8, CTX-M-9, and CTX-M-25 (Bonnet, 2004). The worldwide community and nosocomial spread of these enzymes is most commonly associated with E. coli ST131 producing CTX-M-15 (Karim et al., 2001). However, in Proteus spp., CTX-M-15 is very rarely identified except in a Russian study showing a high prevalence of CTX-M15 between 2013 and 2014 in $>90 \%$ of $P$. mirabilis (Fursova et al., 2015). In Proteus spp., CTX-M-2, -3, and -14 are the most prevalent variants (Bonnet, 2004). In Japan, CTX-M-2producing $P$. mirabilis isolates are extremely prevalent (Nakama et al., 2016), but also those producing the variants CTX-M-10 and CTX-M-14 (Nakama et al., 2016). The prevalence of ESBLproducing $P$. mirabilis isolates has increased steadily in Japan to a dramatically high level from 2000 to 2004 (46.2\%) (Nakano et al., 2012), much higher than in France (6.9\%) (Chanal et al., 2000) 
or in the United States (9.5\%) (Saurina et al., 2000). Nakama et al. (2016) recently reported that the prevalence of CTX-M2 and CTX-M-14-producing P. mirabilis in a Japanese hospital between 2013 and 2014 was $11.1 \%$ of the $P$. mirabilis isolates versus $11.5 \%$ of $E$. coli, and $6.2 \%$ of $K$. pneumoniae isolates. CTXM-2 ESBLs have also been reported in $P$. mirabilis isolates in Spain (Mata et al., 2011), Argentina (Quinteros et al., 2003), and Italy (Pagani et al., 2003).

Nakano et al. (2012) showed the presence of the bla $a_{\mathrm{CTX}-\mathrm{M}-2}$ gene on plasmids of different incompatibility groups, mostly IncT, but also IncW, IncK, IncHI1, IncX, IncN, and IncW. In all isolates, ISEcp 1 was identified 49-bp upstream of the $b l a_{\mathrm{CTX}-\mathrm{M}-2}$ gene, likely responsible of its gene mobilization and bringing the -10 and -35 promoter sequences for its expression (Nakano et al., 2012). Harada et al. (2012) showed the simultaneous localization of the bla $a_{\mathrm{CTX}-\mathrm{M}-2}$ gene on a incT plasmids and on the chromosome of a $P$. mirabilis isolate. The integration of bla $a_{\mathrm{CTX}-\mathrm{M}}$ genes in the chromosome is mediated by transposition via the upstream-located ISEcp1 insertion sequence (Figure 2) (Harada et al., 2012). ISEcp1 has also been involved in the mobilization of the bla $a_{\mathrm{CTX}-\mathrm{M}-14}$ gene in Gaza (Palestine) (Chen et al., 2015). Among the other CTX-M variants, CTXM-3-producing $P$. mirabilis were reported in France (Lartigue et al., 2005), CTX-M-8 producers in Brazil (Bonnet et al., 2000), and CTX-M-14 and CTX-M-27 producers in the United States (Castanheira et al., 2015), and Korea (Yong et al., 2006). Although, in the United States, CTX-M-14 and CTX-M-27 have been more often reported in E. coli, they have been described also in K. pneumoniae and P. mirabilis (Castanheira et al., 2015). In Korea, CTX-M-14 was first identified in K. pneumoniae, E. coli, Shigella sonnei, and then in P. mirabilis between 2002 and 2003 (Yong et al., 2006). More sporadically, CTX-M-8/25 variants in the USA (Castanheira et al., 2015), CTX-M24 in Vietnam between 2009 and 2011 (Biedenbach et al., 2014), have been reported in $P$. mirabilis. All these studies suggest that CTX-Ms are gradually spreading among $P$. mirabilis isolates as for other Enterobacterales. More worryingly, two studies showed the simultaneous diffusion of carbapenemase genes $\left(b l a_{\mathrm{IMP}-6}\right)$ with $b l a_{\mathrm{CTX}-\mathrm{M}-2}$ in Japan (Ohno et al., 2017) and bla $a_{\mathrm{OXA}-48}$ with bla $a_{\mathrm{CTX}-\mathrm{M}-14}$ in Palestine (Chen et al., 2015) (Figure 3).

ESBLs are commonly found in human clinical isolates of $P$. mirabilis, but more rarely from strains of animal origin. The first CTX-M-producing P. mirabilis CTX-M-55, was isolated in 2013 from a macaque imported from Vietnam to France in 2011 (Dahmen et al., 2013). Within veterinary strains of Morganellaceae, bla $a_{\mathrm{CTX}-\mathrm{M}-15}$ (P. mirabilis) and bla $a_{\mathrm{CTX}-\mathrm{M}-1}$ $(P$. rettgeri) have been recently reported. In this study, the bla $a_{\mathrm{CTX}-\mathrm{M}-15}$ gene was even detected in duplicate, one chromosomally- and the other plasmid-located (non-typable) (Schultz et al., 2017).

\section{VEB Enzymes}

VEB, or "Vietnamese ESBL" is an ESBL initially identified in France in a E. coli strain from a Vietnamese patient in 1999 (Poirel et al., 1999). The bla $a_{\mathrm{VEB}-1}$ gene has been reported in several nonfermenting Gram-negative Enterobacterales and Gram-negative rods in Asia, Europe, Africa and America, located either on the chromosome or on plasmids, in a gene cassette in a class 1 integron together with gene cassettes $b l a_{\mathrm{OXA}-10}$, arr-2, and aadB (Poirel et al., 1999), however, the cassette array may contains other cassettes (Kim et al., 2004).

The antibiotic susceptibility panel of VEB-1-producing $P$. mirabilis strains shows an unusual synergy between cefoxitin and cefuroxime (Naas et al., 2000). In P. mirabilis, the bla $a_{\mathrm{VEB}-1}$ gene was first described in Korea (Kim et al., 2004), on a non-transferable genetic support and in Greece in 2010 (Papagiannitsis et al., 2012) on a conjugative $120 \mathrm{~kb}$ plasmid (IncA/C2) carrying also bla $a_{\mathrm{VIM}-1}, b l a_{\mathrm{OXA}-10}$ and $b l a_{\mathrm{TEM}-1}$ genes. The $b l a_{\mathrm{VEB}-1}$ gene was located within a class 1 integron preceded by IS1999 and with gene cassettes aadB, arr2, cmlA5, bla $a_{\mathrm{OXA}-10}$, and aadA1, a truncated $3^{\prime} \mathrm{CS}$ at the sulI gene, and having integrated additional cmlA9-tetR (G) -tetA (G) genes associated with the ISCR6 insertion sequence (Papagiannitsis et al., 2012). On the same plasmid, the bla $a_{\mathrm{VIM}-1}$ gene, with the gene cassettes $\operatorname{aacA} 7, d f r A 1$, and $\operatorname{aadA1}$, were included in an integron with a $5^{\prime} \mathrm{CS}$ fragment interrupted by the IS26$\Delta$ orf6-IS6100 sequence. It seems that the plasmid acquired by this $P$. mirabilis isolate underwent several recombination events between different structures (Papagiannitsis et al., 2012). Several VEB-6-producing $P$. mirabilis isolates have been described later in several infections in France (Siebor and Neuwirth, 2011), in Oman (Potron et al., 2009), in Australia (Zong et al., 2009). VEB6-producing strains have also been isolated from animal samples (Schultz et al., 2015) and raw meat in Switzerland (Seiffert et al., 2013). In this latter study, the bla $a_{\mathrm{VEB}-6}$ gene was located in a class I integron of $\sim 17-\mathrm{kb}$ also carrying multiple resistance genes such as aacA4, aadB, dfrA1, sul1, tet(A), and qnrA1 (Nordmann and Naas, 1994). The bla $\mathrm{VEB}-6$ gene has been recurrently reported on a SGI1-V genetic islands also carrying the qnrA1 gene in a $P$. mirabilis isolate recovered from a blood culture in France in 2009 and in veterinary strains (Schultz et al., 2015). In France in 2012, the bla $a_{\mathrm{VEB}-6}$ gene was reported together with the NDM-1 carbapenemase encoding gene in a novel island called "Proteus genomic island, PGI1-PmPEL" in a P. mirabilis strain isolated from the urine of a patient previously hospitalized in Switzerland (Girlich et al., 2015) (Figures 1, 3 and Table 1).

\section{PER Enzymes}

The PER-1 ESBL was firstly identified in France in a P. aeruginosa isolate from a patient originating from Turkey (Nordmann and Naas, 1994), where this enzyme was shown to spread widely among non-fermenting Gram-negative rods (Bahar et al., 2004). This enzyme is very different in structure and function from other ESBLs (Philippon et al., 2016) and confers resistance to penicillins, cefotaxime, ceftazidime, and aztreonam. The presence of PER-1 in P. mirabilis is anecdotal: one strain has been described in Spain [among fecal Enterobacterales (Philippon et al., 2016)], another was responsible for an outbreak in one hospital in Italy (Pagani et al., 2003). The success of the epidemic PER-1producing $P$. mirabilis isolate in the study by Pagani et al. (2003) in northern Italy might be due, at least in part, to the high levels of resistance reached by the strain, which also produce TEM-2. 
The PER-2 variant, sharing $86 \%$ amino acid identity with PER-1, was detected only in Enterobacterales (E. coli, $K$. pneumoniae, P. mirabilis, S. typhimurium). The spread of PER-2 remains limited to South America (Bauernfeind et al., 1996b). Upstream of the bla $a_{\mathrm{PER}-2}$ gene, an insertion sequence ISPa12 containing the gene encoding a transposase has been identified. ISPa12, or IS1387a, systematically associated with the bla $a_{\text {PER }}$ gene on plasmids or chromosomes, would be involved in the mobilization and expression of PER-1 and PER-2 (Power et al., 2007).

\section{Plasmid-Encoded Cephalosporinases (AmpC)}

In the late 1980s, cephalosporinase (AmpC) genes of chromosomal origin (Citrobacter freundii, E. cloacae, Morganella morganii, Hafnia alvei) were identified on plasmids spreading among Enterobacterales such as: Klebsiella spp., E. coli, P. mirabilis, and Salmonella spp. (Jacoby, 2009). AmpC are class $C \beta$-lactamases that belong to the functional group 1 of Bush and Jacoby (Bush and Jacoby, 2010). These enzymes are characterized by hydrolytic activities toward cephamycins (except ACC-1) (Girlich et al., 2000a) and other expandedspectrum cephalosporins (e.g., cefotaxime, ceftazidime), except cefepime and carbapenems. They are not inhibited by clavulanate and tazobactam but by cloxacillin (Table 1). Most plasmid-encoded AmpCs are constitutively expressed except inducible DHA-1, ACT-1, and CFE-1 (Gaillot et al., 1997). Acquired cephalosporinases in Proteus spp. confer a high-level of resistance to amoxicillin, ticarcillin, cefoxitin, cefotaxime and ceftazidime and a decreased susceptibility to aztreonam. The prevalence of plasmid-mediated cephalosporinases among Enterobacterales varies according to various studies, e.g., from $0.06 \%$ in 1999 to $1.3 \%$ in 2007 in Spain (Mata et al., 2010). In the study from Moland et al. (2006) about Enterobacterales isolates collected in American hospitals between 2001 and 2002, the prevalence of plasmid-mediated AmpCs was higher in K. pneumoniae (3.6\%) than in P. mirabilis (1.4\%). The situation was different in Korea in 2008, where the highest prevalence of plasmid-mediated AmpCs was in P. mirabilis (3.6\%), although it remained low as compared to that of the ESBLs $(12.6 \%$ of $P$. mirabilis isolates) (Song et al., 2011). In this study, the identified plasmid-mediated cephalosporinases were DHA (Bidet et al., 2005), CMY (Decré et al., 2002), FOX-5 (Moland et al., 2006), and ACC-1 (Girlich et al., 2000a). A more recent large study on resistance to ceftazidime-avibactam in the United States showed that, conversely to other Enterobacterales that produce ESBLs, $P$. mirabilis most often carried plasmid-encoded AmpC (pAmpC) (66.7\%) (Mendes et al., 2019).

\section{CMY Enzymes}

CMY-2 (or BIL-1, or LAT-2, originating from C. freundii), and its derivatives, are the most common plasmid-mediated cephalosporinases in P. mirabilis (Mata et al., 2011). A study on AmpC-producing P. mirabilis collected in different European countries from 1999 to 2008 showed the high prevalence of chromosomally located bla $a_{\mathrm{CMY}-2}$ genes (D'Andrea et al., 2011). The bla $\mathrm{CMY}$ gene may also be located on plasmids of IncA/C or IncI1 incompatibility group (Carattoli, 2009). ISEcp1 has been frequently described upstream of the bla $\mathrm{CMY}-2-$ like genes along with other IS, such as IS5, IS10, or IS1294, that are likely involved in the mobilization of these genes (Verdet et al., 2009). In the transposition module called Tn6093, ISEcp1 is located 110-bp upstream of the bla $a_{\mathrm{CMY}}$ gene, and contains fragments of $C$. freundii chromosome on a ColE1-type plasmid (D'Andrea et al., 2011) (Figure 2). Mobilization of the bla $a_{\mathrm{CMY}-2}$ gene by integrative and conjugative islands (ICE) has also been described in Asia (Li et al., 2016), Spain (Mata et al., 2011), and France (Aberkane et al., 2016), in Proteus isolates from humans (Harada et al., 2010) or from livestock, wild animals and pets. The bla $a_{\mathrm{CMY}-2}$ gene has also been described in Switzerland from chicken raw meat on a IncI1 plasmid (Seiffert et al., 2013). Recently, a study by Schultz et al. (2017) showed the chromosomal localization of bla $a_{\mathrm{CMY}-2}$ and $b l a_{\mathrm{DHA}-16}$ genes in Morganellaceae isolates collected from pets. The distribution of CMY variants differs from country to country: bla $a_{\mathrm{CMY}-4}$, $b l a_{\mathrm{CMY}-12}, b l a_{\mathrm{CMY}-14}, b l a_{\mathrm{CMY}-15}, b l a_{\mathrm{CMY}-38}$, and $b l a_{\mathrm{CMY}-45}$ are the most prevalent in Poland, bla $\mathrm{CMY}-16$ in Greece and in Italy (D'Andrea et al., 2011). A strain of $P$. mirabilis producing CMY-42, a CMY-2 variant, was collected in Egypt (Helmy and Wasfi, 2014). Other point-mutation variants of CMY-2 have been identified in $P$. mirabilis likely inserted into the chromosome. This is the case for CMY-3 (Bret et al., 1998) in France; CMY4, $-12,-14$, and -15 in Poland from 1999 to 2001 (Literacka et al., 2004), in Tunisia in 1998 (Verdet et al., 1998), and in France in 2002 (Decré et al., 2002); CMY-15 in P. mirabilis and P. vulgaris (Mokracka et al., 2012); and CMY-16 identified in Italy in 2003 (D’Andrea et al., 2006).

\section{DHA-1}

DHA-1 is the inducible chromosome-encoded cephalosporinase from M. morganii (Verdet et al., 2000). The bla $a_{\mathrm{DH}-1}$ gene was firstly detected plasmid-encoded in a Salmonella enterica isolate from Saudi Arabia in 1997 (Gaillot et al., 1997). Then, dissemination of DHA-1-producing K. pneumoniae has been reported in Taiwan in 2002 (Yan et al., 2002). This plasmidacquired cephalosporinase has been reported for the first time in a P. mirabilis isolate in 2005 in France (Bidet et al., 2005) and in Korea (Yong et al., 2005). Yong et al. (2005) showed the high prevalence of DHA-1-producing Enterobacterales in one hospital in Korea. In this hospital, among the cefoxitin resistant isolates $32 \%$ were $K$. oxytoca, $21.1 \%$ were $K$. pneumoniae, $8.3 \%$ were $P$. mirabilis and $2.7 \%$ were E. coli. All producing the DHA-1 enzyme (Yong et al., 2005). Usually, the bla $a_{\mathrm{DHA}-1}$ gene is located downstream of its $a m p R$ regulatory gene, divergently transcribed, and with overlapping promoters, on conjugative plasmids. They were mobilized and inserted into a complex integron, probably as a result of integrase-mediated recombination (Verdet et al., 2000). Such events have also led to the integration of a fragment containing $b l a_{\mathrm{DHA}-1}$ gene and its $a m p R$ regulatory gene downstream of $b l a_{\mathrm{NDM}-1}$ into the PGIPmPEL, also carrying bla $\mathrm{VEB}_{-6}$ gene in a strain of $P$. mirabilis described in France in 2015 (Girlich et al., 2015) (Figure 3). DHA1 has also been identified sporadically in P. vulgaris in Poland in 2012 (Mokracka et al., 2012). 


\section{FOX Enzymes}

The FOX family is a distinct family of AmpCs in terms of protein sequence identity (Papp-Wallace et al., 2014). The substrate specificity of this class $C \beta$-lactamase includes cephamycins. The $b l a_{\text {FOX }}$ gene is widely disseminated in the United States on IncA/C and pMG252 plasmids and is often associated with the plasmid mediated quinolone resistance gene qnr (Papp-Wallace et al., 2014). FOX $\beta$-lactamases have also been described in Europe (Bauernfeind et al., 1997), South America (Gonzalez Leiza et al., 1994), United Kingdom and Ireland (Manoharan et al., 2012) in E. coli, Enterobacter spp. and Klebsiella spp. isolates. FOX-5-producing P. mirabilis isolates have been detected only once in the United States in 2002 (Moland et al., 2006).

\section{ACC-1}

ACC-1 is another family of plasmid-encoded cephalosporinase originating from the Enterobacterales species $H$. alvei (Girlich et al., 2000b). ACC-1 was detected simultaneously in strains of E. coli and P. mirabilis in the same patient in France (Girlich et al., 2000a). K. pneumoniae, Salmonella spp. and P. mirabilis isolates producing ACC-1 have been collected in several wards of a Tunisian hospital (Rhimi-Mahjoubi et al., 2002) and in Spain (Mata et al., 2010). Production of ACC-1 is particularly suspected in isolates that are resistant to ceftazidime, without any synergy in the presence of clavulanate, together with full susceptibility to cefoxitin (in fact cefoxitin behaves as an inhibitor) and of decreased susceptibility to cefpirome (Girlich et al., 2000a) (Figure 1). Of note, the production of ACC-1 can be masked by the production of an ESBL. The 112-kb plasmids identified in $P$. mirabilis and E. coli carrying $b l a_{\mathrm{ACC}-1}$ did not carry the $a m p R$ gene upstream of $b l a_{\mathrm{ACC}-1}$ and the production of this cephalosporinase was constitutive (Girlich et al., 2000a).

\section{Carbapenemases in Proteus spp.}

Carbapenems (imipenem, ertapenem, meropenem, doripenem) remain in many countries the "last resort" antibiotics for the treatment of severe infection caused by ESBL-producing Enterobacterales. The recent emergence and rapid spread of carbapenemase-producing Enterobacterales (CPE) is a major public health issue as clinical therapeutic options are considerably limited. Invasive infections caused by CPE are often linked to a high mortality rate. Acquired carbapenemases identified in Proteus spp. are (i) Ambler class A carbapenemases such as KPC-2, (ii) metallo- $\beta$-lactamases (MBLs, Ambler class B) VIM-1, IMP-type and NDM-1, and (iii) carbapenem-hydrolyzing Ambler class D $\beta$-lactamases (CHDLs) such as OXA-48 or more intriguingly OXA-23, OXA-40 and OXA-58 (carbapenemases specifically identified in Acinetobacter spp.). In Europe, the most prevalent carbapenemases are KPC, NDM, VIM and OXA-48. In United States and in Japan, the most prevalent carbapenemase is KPC and IMP respectively (Naas et al., 2008; Ohno et al., 2017).

The detection of CPEs is essential in the control of infections and can have an impact on the treatment. Unfortunately, this detection is particularly difficult in Proteus spp. in which the level of resistance to carbapenems remains low despite the production of a carbapenemase (Girlich et al., 2017). In addition, the "swarming" of Proteus spp. does not allow the efficient detection of CPE using phenotypic inhibition methods with disks containing dipicolinic acid (or ethylene diamine tetraacetic acid, EDTA), boronic acid and temocillin (van Dijk et al., 2014). On top of that, Morganellaceae (particularly P. mirabilis) possess intrinsic decreased susceptibility to imipenem (but not meropenem and ertapenem), mainly due to penicillin binding proteins (PBPs) with weak affinity or porin loss. Consequently, ertapenem and/or meropenem have to be used to screen carbapenemase producers in Morganellaceae.

\section{Ambler Class A Carbapenemase: KPC-2}

Initially identified in a K. pneumoniae isolate from the US (Yigit et al., 2001), KPC-2 and variants went global, becoming the most common carbapenemase that has disseminated widely among Enterobacterales (Naas et al., 2008) P. aeruginosa (Wolter et al., 2009) and more rarely in A. baumannii (Robledo et al., 2010). It confers resistance to all $\beta$-lactams, including carbapenems, cephalosporins, cephamycins, penicillins and monobactams. The bla $a_{\mathrm{KPC}}$ genes are most commonly located on transferable plasmids of different sizes and structures, within transposons of Tn3 type, Tn4401 (Naas et al., 2008). Tn4401, $10 \mathrm{~kb}$ long, is bracketed by two imperfect repeats of 39-bp. It contains the genes encoding a transposase and a resolvase and two ISs, ISKpn6 and ISKpn7 (Naas et al., 2008) or ISKpn6-like and ISKpn8 (Shen et al., 2009). In P. mirabilis, KPC-2 was identified for the first time in 2008 in the blood culture of a diabetic patient in the United States (Tibbetts et al., 2008). Then, KPC2 producing $P$. mirabilis isolates have been identified in China (Shen et al., 2009; Sheng et al., 2010; Hu et al., 2012), Colombia (Cuzon et al., 2011)Brazil (Cabral et al., 2015), and Italy (Di Pilato et al., 2016). The bla $a_{\mathrm{KPC}-2}$ gene was located on 45-54 kb conjugative plasmids, surrounded by ISKpn 8 and ISKpn6-like, as the structure described in K. pneumoniae KP048 (Shen et al., 2009) (Figure 3). In Brazil, the identification of KPC-2 at the origin of carbapenem resistance in $P$. mirabilis is worrying as it results pandrug resistant isolates. Indeed $P$. mirabilis is naturally resistant to polymyxins, one of the only drugs showing some efficacy against KPC-producers. However, this discovery is not entirely unexpected, given the number of publications reporting the spread of the bla $a_{\mathrm{KPC}}$ genes between different Gram-negative bacterial species such as $K$. pneumoniae and $P$. aeruginosa in the same hospital (Recife, Brazil) (Cabral et al., 2015).

\section{Metallo- $\beta$-Lactamases}

The MBLs are structural Ambler class B $\beta$-lactamases and functional group 3 enzymes (Bush and Jacoby, 2010). MBLs hydrolyze all $\beta$-lactams except aztreonam. MBLs have one or two divalent zinc ions in their active site and are inhibited in vitro by cation chelators such as EDTA. MBL are classified into 3 subclasses according to their protein sequence: B1, B2, and B3. Class B1-like and plasmid-encoded enzymes such as NDM, VIM, and IMP have emerged in clinical settings in both Enterobacterales and non-fermenting Gram-negative bacilli.

\section{IMP}

IMP carbapenemase for "imipenemase" is the most common carbapenemase in Enterobacterales in Japan (Ohno et al., 2017). IMP-1 was originally described in a strain of $P$. aeruginosa in 
Japan in 1991 (Watanabe et al., 1991). Then, also in Japan, the bla IMP-1 gene has been described to be located on a IncP9 conjugative plasmid, in a Serratia marcescens isolate (Osano et al., 1994). The bla IMP gene is, most of the time, located on a broad host range plasmid, such as IncL/M and IncA/C. On these plasmids, the bla $\mathrm{IMP}$ gene is most often part of a class 1 integron as a gene cassette, along with other resistance determinants encoding aminoglycoside acetyltransferase (e.g., aacA4), aminoglycoside adenilyltransferase (aad1, aad2) or narrow-spectrum oxacillinases (e.g., bla $a_{\mathrm{OXA}-1,-2,-10}$ ). Ohno et al. showed the steady increase in the prevalence of CPE from 2010 to 2013 in a Japanese hospital; from $0.1 \%$ in 2010, $0.2 \%$ in $2011,0.2 \%$ in 2012 to $0.8 \%$ in 2013 (Ohno et al., 2017). In this study, all of these strains (17 out of 4875 isolates) produced IMP-6 along with the ESBL CTX-M-2 for most of them (Ohno et al., 2017). In addition, a multi-center study on metallo$\beta$-lactamase producing Enterobacterales (MBL) showed a global CPE prevalence of $0.42 \%$ in a Kinki hospital in Japan between 2000 and 2002 comprising 96 IMP-1, IMP-2 and VIM-2, positive isolates but no Proteus spp. (Nishio et al., 2004). The acquisition of $b l a_{\mathrm{IMP}}$-like genes by $P$. mirabilis seems to be a rare event, since only two descriptions of IMP-27 carried by a class 2 integron has been reported to date (Dixon et al., 2016). These isolates were collected in 2009 and 2015 from two different patients who were from two different states in the upper plain region of the United States. An IMP-27-producing P. mirabilis was also identified in the United States in a soil sample in a pig farm in 2015 (Mollenkopf et al., 2017). The bla $a_{\mathrm{IMP}-27}$ gene was located on an IncQ1 plasmid. It has been suggested in this study that the dissemination of this plasmid among Enterobacterales could be facilitated by the use of ceftiofur in pig farms in the United States (Mollenkopf et al., 2017).

A more recent study by Ramos et al. (2017) reports an outbreak of 10 IMP-1 producing $P$. mirabilis isolates (two distinct clones) in a tertiary hospital in São Paulo, Brazil, in 2015. In this study the $b l a_{\mathrm{IMP}-1}$ gene was carried on a novel class 1 integron, In 1359, on a conjugative plasmid belonging to the IncA/C group. More worrisome was the coproduction of additional plasmidmediated resistance genes $b l a_{\mathrm{KPC}-2}, b l a_{\mathrm{CTX}-\mathrm{M}-14}$ and $r m t B-1$.

\section{VIM-1}

VIM-1 belongs to a second major group of class B1 MBLs. It was first described in 1997 in Italy, hence its name: "Verona integron-encoded MBL" in a clinical strain of $P$. aeruginosa (Lauretti et al., 1999). VIM-type enzymes are predominant in $P$. aeruginosa isolates, but they may also be found in Enterobacterales, especially in Mediterranean countries such as Italy, Greece and Tunisia (Mojica et al., 2016). The bla $a_{\mathrm{VIM}}$ genes are generally inserted into class 1 integrons that are themselves located on plasmids of IncN or IncFI/FII groups, or integrated into the chromosome (Mojica et al., 2016). More than 66 variants have been described (Naas et al., 2017) $\left(\mathrm{BLDB}^{1}\right.$, last accessed 12/12/19) that can be divided in three distinct sub-families VIM-1-like (31 variants),

\footnotetext{
${ }^{1}$ http://www.bldb.eu/
}

VIM-2-like (33 variants; 90\% AA sequence identity with VIM1) and VIM-7-like (2 variants; $80 \%$ AA sequence identity with VIM-1).

In $P$. mirabilis, the prevalence of VIM-1 is especially high in Greece, where the first strain was described in 2006 (Papagiannitsis et al., 2012) and where the spread has been described not only in hospital settings, but also in the community (Tsakris et al., 2007). The bla $a_{\mathrm{VIM}-1}$ gene is located on class 1 integrons, inserted into the chromosome with genes aacA7, dhfr, and aadA (Vourli et al., 2006) or in conjugative plasmids carrying also bla $a_{\mathrm{VEB}-1}, b l a_{\mathrm{OXA}-10}, b l a_{\mathrm{TEM}-1}$ genes (Papagiannitsis et al., 2012). In addition, an outbreak of 13 P. mirabilis isolates producing VIM-1 and CMY-99 was recently reported in Bulgaria (Markovska et al., 2017). In this clone, the bla $a_{\mathrm{VIM}-1}$ gene was located into a class 1 integron that also contained the aminoglycoside $\left(\operatorname{aac}\left(6^{\prime}\right)-I b\right.$, ant $\left.\left(3^{\prime \prime}\right)-I a\right)$ and trimethoprim ( $\operatorname{dhfrA1)}$ resistance determinants (Markovska et al., 2017) Two other isolates of $P$. mirabilis co-producing VIM1 and CMY-16 have also been described in the Netherlands (van Dijk et al., 2014).

\section{NDM-1}

The "New Delhi metallo- $\beta$-lactamase-1" (NDM-1) was initially identified in 2008 in a K. pneumoniae isolate recovered from a patient repatriated from India. As other MBLs, this enzyme confers resistance to carbapenems and all $\beta$-lactams with the exception of aztreonam (Yong et al., 2009). Endemic in the India sub-continent, the bla $a_{\mathrm{NDM}-1}$ gene has spread throughout the world, not only in Enterobacterales, but also in various species such as Vibrio cholerae, Pseudomonas spp. and Acinetobacter spp. In Enterobacterales, the $b l a_{\mathrm{NDM}-1}$ gene is rarely located on the chromosome, but most often on conjugative plasmids from different incompatibility groups (Poirel et al., 2011) such as IncA/C, IncF, IncL/M, IncHI1B or more recently IncX3 of $\sim 40 \mathrm{~kb}$ in size (Zhang et al., 2016). The immediate genetic environment of bla $a_{\mathrm{NDM}}$ is characterized by an upstream inserted ISAba125 that originated from A. baumannii (Poirel et al., 2011) and a downstream-located ble $e_{\mathrm{MBL}}$ gene, encoding a bleomycin binding protein, $\mathrm{BRP}_{\mathrm{MBL}}$ (Dortet et al., 2017). It has recently been evidenced an association of bla $a_{\mathrm{NDM}}$ gene with ISCR1 insertion sequence, one of the most widespread mechanisms for the diffusion of clinically relevant antibiotic resistance genes (Liu et al., 2013). The presence of bla $a_{\mathrm{NDM}}$ in Proteus spp. clinical isolates is still episodic in New Zealand (Williamson et al., 2012), in China (bla $a_{\mathrm{NDM}-5}$ ) (Zhang et al., 2016), in Bulgaria (P. rettgeri) in 2016 (Pfeifer et al., 2017), in Vietnam (Tran et al., 2015). However, the $b l a_{\mathrm{NDM}-1}$ gene was the first carbapenemase gene identified on a genomic island (PGI-1, PGI1-PmPEL) together with the $b l a_{\mathrm{VEB}-6}$ gene in $P$. mirabilis isolate recovered from the urine of an hospitalized patient in France in 2012 (Girlich et al., 2015) (Figures 1, 3). Surprisingly, in P. mirabilis, the level of resistance to carbapenems conferred by NDM-1 remains very low; with the exception of imipenem (MIC $32 \mu \mathrm{g} / \mathrm{mL}$ ). Indeed, the MIC of ertapenem $(0.25 \mu \mathrm{g} / \mathrm{mL})$ and meropenem $(0.75 \mu \mathrm{g} / \mathrm{mL})$ remain within the sensitivity range defined by the Clinical and Laboratory Standards Institute (CLSI) (Table 1). More recently, Baraniak et al. (2016) also identified bla $a_{\mathrm{NDM}-1}$ 
and $b l a_{\mathrm{VEB}-6}$ genes on the chromosome of a P. mirabilis isolate in a patient from Afghanistan on a Tn125 transposon.

The $b l a_{\text {NDM-1 }}$ gene was also identified in China on a 58 -kb conjugative plasmid inserted within a class 1 integron downstream of ISCR1 (qacE $\Delta 1 /$ sul1-ISCR1-1-trpF-ble $\mathrm{MBL}^{-}$ bla $\left.a_{\mathrm{NDM}-1}-\Delta \mathrm{ISAba125}\right)$ in a $P$. mirabilis isolate containing also a SGI1-Z genomic island (Qin et al., 2015). With the description of this strain, we might hypothesize that the chromosomal location of $b l a_{\mathrm{NDM}-1}$ gene inside a SGI or a PGI-like structure might result from consecutive genetic rearrangements starting by acquisition of a $b l a_{\mathrm{NDM}-1}$ carrying plasmid in a SGI/PGI carrying $P$. mirabilis isolate and subsequent mobilization of the Tn125 transposon from the plasmid into the SGI/PGI.

\section{Carbapenem-Hydrolyzing Class D $\beta$-Lactamases (CHDLs)}

Among the Ambler class D $\beta$-lactamases only few variants with carbapenem-hydrolyzing activities have been characterized. Among them, OXA-48 is the most frequently identified in Enterobacterales. Whereas OXA-23, OXA-40, OXA-58, OXA143 are mostly identified in Acinetobacter baumannii isolates.

\section{OXA-48}

OXA-48, is a CHDL, originally identified in a K. pneumoniae isolate in Turkey (Poirel et al., 2004). Acquisition of the IncL conjugative plasmid carrying the bla $\mathrm{OXA}-48$ gene has been shown to be intra and inter-species (Fursova et al., 2015). This $62.5-\mathrm{kb}$ plasmid has now widely diffused among Enterobacterales (Poirel et al., 2012). Surprisingly, Proteus spp. OXA-48 producers have only been very rarely reported. The only descriptions of OXA- 48 producing $P$. mirabilis isolates is from Palestine (strain isolated in 2012) (Chen et al., 2015) and from Russia (study reporting data from 2013 to 2014) (Fursova et al., 2015). In Moscow's hospital, OXA-48-like carbapenemases were detected in $23.3 \%$ of P. mirabilis isolates due to the dissemination of one clone, and in $55.3 \%$ of $K$. pneumoniae isolates, due to the dissemination of one plasmid (Fursova et al., 2015). The Palestinian study focused on a single strain isolated from a urine sample and shows the simultaneous presence of $b l a_{\mathrm{OXA}-48}, b l a_{\mathrm{CTX}-\mathrm{M}-14}, b l a_{\mathrm{TEM}-1}$ genes and of 13 other resistance genes including resistance to aminoglycosides [aph(3)-Ia, aadA1, aac(3)-IIa, aph(3)-VIb, strA, $s t r B]$, fluoroquinolones ( $q n r D)$, streptothricin (sat-1), phenicols (catA1 and cat), tetracycline tet $(J)$, sulfonamide-trimethoprim (sul2 and dfrA1), and 27 genes related to the resistance to antiseptics and toxic products, including arsR (arsenic), cutEF (copper), merA (mercury), and emrD (benzalkonium chloride) (Chen et al., 2015) (Figure 3).

Besides the OXA-48 family, which is exclusively found in Enterobacterales and is thus expected to be found in Proteus, other CHDLs such as OXA-23, OXA-40, OXA-58 that have been exclusively identified in Acinetobacter species (Bonnin et al., 2013a) have recently been identified in P. mirabilis (Bonnet et al., 2002; Girlich et al., 2017; Leulmi et al., 2019; Potron et al., 2019).

\section{OXA-23}

OXA-23 is the most widespread CHDL in the world. The progenitor of this gene has been identified in Acinetobacter radioresistens (Poirel et al., 2008). The first reported OXA-23producing (formerly ARI-1) isolate was a carbapenem-resistant A. baumannii detected in Scotland in 1985 (Paton et al., 1993). In this first study, the bla $\mathrm{OXA}-23$ gene in A. baumannii was plasmid located (Paton et al., 1993). In A. baumannii the bla OXA-23 gene can be located on different transposons Tn2006, Tn2007 and Tn2008 (Mugnier et al., 2010). OXA-23 has since been widely detected, always in Acinetobacter isolates, until 2002, when Bonnet et al. (2002) detected this carbapenemase in P. mirabilis. This study investigated the persistence over 3 years of an OXA23-producing P. mirabilis, in different care units in France (1996 to 1999) (Bonnet et al., 2002). In Proteus spp. OXA-23 confers resistance to amoxicillin, amoxicillin + clavulanate, ticarcillin, ticarcilline + clavulanate, and a decreased susceptibility to cephalotin, cefpirome and carbapenems (Table 1). In study of Bonnet et al. (2002) the bla OXA-23 gene was chromosomeencoded, probably resulting from the integration of a plasmid unable to replicate in Enterobacterales. More recently, Österblad et al. (2016) in Finland, and Potron et al. (2019) in France also described the occurrence of the bla $a_{\mathrm{OXA}-23}$ gene in the chromosome of a $P$. mirabilis isolate with a close genetic environment typical of $A$. baumannii with insertion sequences ISAba1, ISAba14 and ISAba125. Other resistance genes would have been inserted together with bla OXA-23 such as sul2, floR, $s t r B$, and $\operatorname{str} A$ (Österblad et al., 2016). In addition, this bla $a_{\text {OXA }-23}$ gene, thought to be restricted to the A. baumannii species, was also incidentally identified on an E. coli plasmid in Singapore (La et al., 2014). Considering the presence of transfer elements and the relatively low hydrolytic activity toward carbapenems conferred by this enzyme, it is feared that the bla OXA-23 genes have already silently disseminated among Enterobacterales, especially in Proteus spp. Indeed, our recent data (RB, DG, LD, TN) suggest that OXA-23 is increasingly identified in Proteus spp., although it is mostly ignored because of the low level of resistance conferred by this enzyme.

\section{OXA-58}

OXA-58 is a widespread CHDL in imipenem-resistant Acinetobacter spp., but has also been described outside the genus Acinetobacter, in K. pneumoniae, E. coli, Pseudomonas spp. and Burkholderia spp. in Sierra Leone (Moland et al., 2006). The bla $a_{\mathrm{OXA}-58}$ gene may be chromosome- or plasmid-encoded (Bonnin et al., 2013a). We have recently described in P. mirabilis the chromosomal location with tandem repeats of a fragment containing simultaneously bla $a_{\mathrm{OXA}-58,}$ bla $a_{\mathrm{AmpC}}$ genes of an uncultured species and a truncated ISAba3 (Girlich et al., 2017). The integration of these fragments took place at the XerC-XerD recombinase recognition site (Girlich et al., 2017). Tandem amplifications often involve repeat elements, insertion sequences, or rRNA (Brochet et al., 2008) operons (Figure 3 and Table 1). In this $P$. mirabilis isolate OXA-58 conferred resistance to temocillin, as well as resistance to the piperacillin-tazobactam combination and a slight decrease in susceptibility to ertapenem (MIC $0.125 \mathrm{mg} / \mathrm{L}$ ) (Girlich et al., 2017). The association of these three features is a good marker of the presence of and OXA-like carbapenemase. 


\section{OXA-24/40}

The bla OXA-24/40 gene was identified initially in 1997 from isolates that were part of an outbreak in Spain, and since then it has never been detected in strains other than A. baumannii and mostly on the Iberic peninsula (Evans and Amyes, 2014). However, very recently, an MDR P. mirabilis isolate harboring the

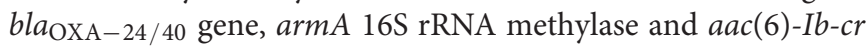
genes was found for the first time in Algeria (Moland et al., 2006).

\section{Mechanisms of Non-enzymatic $\beta$-Lactam Resistance}

The relative non-susceptibility of Morganellaceae to imipenem has not caused major clinical problems, but the inability of imipenem to eradicate $P$. mirabilis from soft-tissue infections was reported, as did post-treatment colonization by the organism (Dirksen et al., 1986). Some P. mirabilis isolates are more resistant, with imipenem MICs ranging from 16 to $64 \mathrm{mg} / \mathrm{L}$, and one step mutants with these resistance levels can be isolated in vitro. However, Villar (1997) showed that loss of the $26 \mathrm{kDa}$ OMP and decreased expression of the 41 and $44 \mathrm{kDa}$ OMP did not themselves confer resistance to these compounds. Rather, some evidence suggest that the imipenem resistance reflects changes in penicillin binding proteins (PBP2) (Villar, 1997). PBP 2 production was expected to decline, which may explain the cross-resistance to imipenem and mecillinam. Neuwirth et al. showed that this was not the case and instead observed a decreased affinity of PBP2 for imipenem and a smaller amount of PBP1A (Neuwirth et al., 1995). Tsai et al. (2015) identified that the ImpR OMP, increased in P. mirabilis $h f q$ mutant, contributed to a decrease in carbapenem susceptibility. ImpR was a homolog of Salmonella YbfM, a porin for chitobiose and subjected to MicM (a small RNA) regulation (Tsai et al., 2015). Raimondi et al. (1991) showed that deficiency in a major outer membrane protein of $37 \mathrm{kDa}$, was responsible for the very low permeability of the membrane of $P$. rettgeri and thus, for high-level resistance to both meropenem and imipenem. This protein was earlier identified as the major non-specific porin of $40 \mathrm{kDa}$ in $P$. mirabilis and of $37 \mathrm{kDa}$ in P. vulgaris, M. morganii, P. rettgeri, and Providencia alcalifaciens (Mitsuyama et al., 1987). The lack of this porin resulted in a marked decrease in susceptibility to tetracycline and cephalosporins, except cefoperazone (Mitsuyama et al., 1987).

\section{POTENTIAL P. MIRABILIS ANIMAL-TO-HUMAN TRANSMISSION}

The spread of SGI1/PGI1 in multidrug resistant $P$. mirabilis isolates in animals does not seem to be a sporadic phenomenon and should be the subject of sustained attention. According to Schultz et al. (2015), the sudden high prevalence of SGI/PGI1containing Proteus spp. in veterinary studies suggests (i) either that these elements have not been detected in previous studies on Proteus spp. or (ii) a very rapid dissemination of these strains since their first description in 2011 (Siebor and Neuwirth, 2011). These data also suggest the possible way of transmission between man and pet or man and animals from food. P. mirabilis should be considered by hygiene committees as a potential reservoir of resistance genes in pets. In addition to the risk of animalto-human transmission, there is a risk of gene transmission between bacterial species via SGI/PGI and plasmids as this was the case between $P$. mirabilis and other Enterobacterales or other non-related species such as A. baumannii.

\section{CONCLUSION}

Proteus mirabilis can be found in a wide variety of environments, including soil, water sources, and sewage, but it is predominantly a commensal of the gastrointestinal tracts of humans and animals. $P$. mirabilis is a bacterium of medical importance and usually responsible for most of the common nosocomial opportunistic infections, including those of wounds, the eye, the gastrointestinal tract, and the urinary tract, it is an agent of catheter biofilm formation, quickly fouling the surface of a newly inserted urinary catheter. This review aimed to collect all the genetic mechanisms associated with the multidrug resistance phenotype of Proteus spp. focusing on P. mirabilis. A second objective was to highlight the potential reservoir role of these species for antibiotic resistance genes. We have reported globally the emergence and prevalence of these determinants of antimicrobial resistance in certain bacteria and their acquisition by Proteus spp. Although Armbruster et al. (2018) postulated that plasmids are not a defining feature for $P$. mirabilis, we have listed here several plasmids harboring antibiotic resistance genes including resistance to aminoglycosides, to quinolones and to $\beta$-lactams within conjugative and non-conjugative but mobilizable elements (mic). Concerning antibiotic resistance determinants, similarly to Salmonella spp., P. mirabilis carries integrative and conjugative elements (ICEPm) and other ICEs in the SXT/R391 family that can self-replicate and self-transfer to other strains and species, transferring virulence genes and antibiotic resistance. One of the best examples are genetic exchanges that occurred between an Acinetobacter species and $P$. mirabilis, resulting in the acquisition and expression of two $\beta$-lactamase genes, bla $a_{\mathrm{OXA}-58}$ and $b l a_{\mathrm{AmpC}}$, at the same chromosomal locus.

\section{AUTHOR CONTRIBUTIONS}

All authors listed have made a substantial, direct and intellectual contribution to the work, and approved it for publication.

\section{FUNDING}

This work was supported by the Assistance Publique - Hôpitaux de Paris (AP-HP), the University of Paris-Saclay, the Laboratory of Excellence in Research on Medication and Innovative Therapeutics (LERMIT) supported by a grant from the French National Research Agency (ANR-10-LABX-33) and by the Joint Programming Initiative on Antimicrobial Resistance (JPIAMR) DesInMBL (ANR-14-JAMR-002). 


\section{REFERENCES}

Aberkane, S., Compain, F., Decré, D., Dupont, C., Laurens, C., Vittecoq, M., et al. (2016). High prevalence of SXT/R391-related integrative and conjugative elements carrying blaCMY-2 in Proteus mirabilis isolates from gulls in the south of France. Antimicrob. Agents Chemother. 60, 1148-1152. doi: 10.1128/AAC. 01654-15

Abreu, A. G., Marques, S. G., Monteiro-Neto, V., de Carvalho, R. M. L., and Gonçalves, A. G. (2011). Nosocomial infection and characterization of extended-spectrum $\beta$-lactamases-producing Enterobacteriaceae in Northeast Brazil. Rev. Soc. Bras. Med. Trop. 44, 441-446. doi: 10.1590/s003786822011000400008

Adeolu, M., Alnajar, S., Naushad, S., and S Gupta, R. (2016). Genomebased phylogeny and taxonomy of the 'Enterobacteriales': proposal for Enterobacterales ord. nov. divided into the families Enterobacteriaceae, Erwiniaceae fam. nov., Pectobacteriaceae fam. nov., Yersiniaceae fam. nov., Hafniaceae fam. nov., Morganellaceae fam. nov., and Budviciaceae fam. nov. Int. J. Syst. Evol. Microbiol. 66, 5575-5599. doi: 10.1099/ijsem.0.001485

Ahmed, A. M., Hussein, A. I. A., and Shimamoto, T. (2007). Proteus mirabilis clinical isolate harbouring a new variant of Salmonella genomic island 1 containing the multiple antibiotic resistance region. J. Antimicrob. Chemother. 59, 184-190. doi: 10.1093/jac/dkl471

Alabi, O. S., Mendonça, N., Adeleke, O. E., and Da Silva, G. J. (2017). Molecular screening of antibiotic-resistant determinants among multidrugresistant clinical isolates of Proteus mirabilis from SouthWest Nigeria. Afr. Health Sci. 17, 356-365. doi: 10.4314/ahs.v17i2.9

Albornoz, E., Lucero, C., Romero, G., Rapoport, M., Guerriero, L., Andres, P., et al. (2014). Analysis of plasmid-mediated quinolone resistance genes in clinical isolates of the tribe Proteeae from Argentina: first report of $q n r D$ in the Americas. J. Glob. Antimicrob. Resist. 2, 322-326. doi: 10.1016/j.jgar.2014. 05.005

Ambler, R. P. (1980). The structure of beta-lactamases. Philos. Trans. R. Soc. Lond. B Biol. Sci. 289, 321-331.

Armbruster, C. E., Mobley, H. L. T., and Pearson, M. M. (2018). Pathogenesis of Proteus mirabilis infection. EcoSal Plus 8: 10.1128/ecosalplus.ESP-0009-2017.

Arpin, C., Dubois, V., Coulange, L., André, C., Fischer, I., Noury, P., et al. (2003). Extended-spectrum $\beta$-lactamase-producing Enterobacteriaceae in community and private health care centers. Antimicrob. Agents Chemother. 47, 3506-3514. doi: 10.1128/aac.47.11.3506-3514.2003

Bahar, G., Eraç, B., Mert, A., and Gülay, Z. (2004). PER-1 production in a urinary isolate of Providencia rettgeri. J. Chemother. 16, 343-346. doi: 10.1179/joc.2004. 16.4.343

Bailey, J. K., Pinyon, J. L., Anantham, S., and Hall, R. M. (2011). Distribution of the blaTEM gene and blaTEM-containing transposons in commensal Escherichia coli. J. Antimicrob. Chemother. 66, 745-751. doi: 10.1093/jac/dkq529

Baraniak, A., Izdebski, R., Fiett, J., Gawryszewska, I., Bojarska, K., Herda, M., et al. (2016). NDM-producing Enterobacteriaceae in Poland, 2012-14: inter-regional outbreak of Klebsiella pneumoniae ST11 and sporadic cases. J. Antimicrob. Chemother. 71, 85-91. doi: 10.1093/jac/dkv282

Bauernfeind, A., Schweighart, S., and Chong, Y. (1989). Extended broad spectrum $\beta$-lactamase in Klebsiella pneumoniae including resistance to cephamycins. Infection 17, 316-321. doi: 10.1007/bf01650718

Bauernfeind, A., Stemplinger, I., Jungwirth, R., Ernst, S., and Casellas, J. M. (1996a). Sequences of beta-lactamase genes encoding CTX-M-1 (MEN-1) and CTX-M-2 and relationship of their amino acid sequences with those of other betalactamases. Antimicrob. Agents Chemother. 40, 509-513. doi: 10.1128/aac.40. 2.509

Bauernfeind, A., Stemplinger, I., Jungwirth, R., Mangold, P., Amann, S., Akalin, E., et al. (1996b). Characterization of beta-lactamase gene blaPER-2, which encodes an extended-spectrum class A beta-lactamase. Antimicrob. Agents Chemother. 40, 616-620. doi: 10.1128/aac.40.3.616

Bauernfeind, A., Wagner, S., Jungwirth, R., Schneider, I., and Meyer, D. (1997). A novel class C beta-lactamase FOX-2 in Escherichia coli conferring resistance to cephamycins. Antimicrob. Agents Chemother. 41, 2041-2046. doi: 10.1128/aac. 41.9.2041

Bidet, P., Verdet, C., Gautier, V., Bingen, E., and Arlet, G. (2005). First description of DHA-1 AmpC beta-lactamase in Proteus mirabilis. Clin. Microbiol. Infect. 11, 591-592. doi: 10.1111/j.1469-0691.2005.01178.x
Biedenbach, D. J., Bouchillon, S. K., Hoban, D. J., Hackel, M., Phuong, D. M., Nga, T. T. T., et al. (2014). Antimicrobial susceptibility and extended-spectrum beta-lactamase rates in aerobic gram-negative bacteria causing intra-abdominal infections in Vietnam: report from the Study for Monitoring Antimicrobial Resistance Trends (SMART 2009-2011). Diagn. Microbiol. Infect. Dis. 79, 463-467. doi: 10.1016/j.diagmicrobio.2014.05.009

Biendo, M., Thomas, D., Laurans, G., Hamdad-Daoudi, F., Canarelli, B., Rousseau, F., et al. (2005). Molecular diversity of Proteus mirabilis isolates producing extended-spectrum beta-lactamases in a French university hospital. Clin. Microbiol. Infect. 11, 395-401. doi: 10.1111/j.1469-0691.2005.01147.x

Bonnet, R. (2004). Growing group of extended-spectrum beta-lactamases: the CTX-M enzymes. Antimicrob. Agents Chemother. 48, 1-14. doi: 10.1128/aac. 48.1.1-14.2004

Bonnet, R., Marchandin, H., Chanal, C., Sirot, D., Labia, R., De Champs, C., et al. (2002). Chromosome-encoded class D beta-lactamase OXA-23 in Proteus mirabilis. Antimicrob. Agents Chemother. 46, 2004-2006. doi: 10.1128/aac.46.6. 2004-2006.2002

Bonnet, R., Sampaio, J. L., Labia, R., De Champs, C., Sirot, D., Chanal, C., et al. (2000). A novel CTX-M beta-lactamase (CTX-M-8) in cefotaxime-resistant Enterobacteriaceae isolated in Brazil. Antimicrob. Agents Chemother. 44, 19361942. doi: 10.1128/aac.44.7.1936-1942.2000

Bonnin, R. A., Nordmann, P., and Poirel, L. (2013a). Screening and deciphering antibiotic resistance in Acinetobacter baumannii: a state of the art. Expert Rev. Anti Infect. Ther. 11, 571-583. doi: 10.1586/eri.13.38

Bonnin, R. A., Poirel, L., Benoit-Cattin, T., and Nordmann, P. (2013b). Ceftazidime-susceptible and imipenem-non-susceptible OXA-58-producing Acinetobacter baumannii from the Comoros archipelago. Int. J. Antimicrob. Agents 41, 297-298. doi: 10.1016/j.ijantimicag.2012.11.002

Bret, L., Chanal, C., Sirot, D., Labia, R., and Sirot, J. (1996). Characterization of an inhibitor-resistant enzyme IRT-2 derived from TEM-2 beta-lactamase produced by Proteus mirabilis strains. J. Antimicrob. Chemother. 38, 183-191. doi: $10.1093 / \mathrm{jac} / 38.2 .183$

Bret, L., Chanal-Claris, C., Sirot, D., Chaibi, E. B., Labia, R., and Sirot, J. (1998). Chromosomally encoded AmpC-type $\beta$-lactamase in a clinical isolate of Proteus mirabilis. Antimicrob. Agents Chemother. 42, 1110-1114. doi: 10.1128/aac.42.5. 1110

Brochet, M., Couvé, E., Zouine, M., Poyart, C., and Glaser, P. (2008). A naturally occurring gene amplification leading to sulfonamide and trimethoprim resistance in Streptococcus agalactiae. J. Bacteriol. 190, 672-680. doi: 10.1128/ jb.01357-07

Bush, K., and Jacoby, G. A. (2010). Updated functional classification of betalactamases. Antimicrob. Agents Chemother. 54, 969-976. doi: 10.1128/AAC. 01009-09

Cabral, A. B., Maciel, M. A. V., Barros, J. F., Antunes, M. M., and Lopes, A. C. S. (2015). Detection of blaKPC-2 in Proteus mirabilis in Brazil. Rev. Soc. Bras. Med. Trop. 48, 94-95. doi: 10.1016/j.jgar.2019.08.026

Cambau, E., Lascols, C., Sougakoff, W., Bébéar, C., Bonnet, R., Cavallo, J.-D., et al. (2006). Occurrence of $q n r A$-positive clinical isolates in French teaching hospitals during 2002-2005. Clin. Microbiol. Infect. 12, 1013-1020. doi: 10. 1111/j.1469-0691.2006.01529.x

Cantón, R., Loza, E., Aznar, J., Castillo, F. J., Cercenado, E., Fraile-Ribot, P. A., et al. (2019). Monitoring the antimicrobial susceptibility of Gram-negative organisms involved in intraabdominal and urinary tract infections recovered during the SMART study (Spain, 2016 and 2017). Rev. Esp. Quimioter. 32, $145-155$.

Carattoli, A. (2009). Resistance plasmid families in Enterobacteriaceae. Antimicrob. Agents Chemother. 53, 2227-2238. doi: 10.1128/aac.01707-08

Castanheira, M., Mills, J. C., Costello, S. E., Jones, R. N., and Sader, H. S. (2015). Ceftazidime-avibactam activity tested against Enterobacteriaceae isolates from U.S. hospitals (2011 to 2013) and characterization of $\beta$-lactamase-producing strains. Antimicrob. Agents Chemother. 59, 3509-3517. doi: 10.1128/AAC. 00163-15

Chanal, C., Bonnet, R., De Champs, C., Sirot, D., Labia, R., and Sirot, J. (2000). Prevalence of beta-lactamases among 1,072 clinical strains of Proteus mirabilis: a 2-year survey in a French hospital. Antimicrob. Agents Chemother. 44, 19301935. doi: 10.1128/aac.44.7.1930-1935.2000

Chen, L., Laham, N. A., Chavda, K. D., Mediavilla, J. R., Jacobs, M. R., Bonomo, R. A., et al. (2015). First report of an OXA-48-producing multidrug-resistant 
Proteus mirabilis strain from Gaza, Palestine. Antimicrob. Agents Chemother. 59, 4305-4307. doi: 10.1128/AAC.00565- 15

Choury, D., Aubert, G., Szajnert, M. F., Azibi, K., Delpech, M., and Paul, G. (1999). Characterization and nucleotide sequence of CARB-6, a new carbenicillin-hydrolyzing beta-lactamase from Vibrio cholerae. Antimicrob. Agents Chemother. 43, 297-301. doi: 10.1128/aac.43.2.297

Choury, D., Szajnert, M.-F., Joly-Guillou, M.-L., Azibi, K., Delpech, M., and Paul, G. (2000). Nucleotide sequence of the blaRTG-2 (CARB-5) gene and phylogeny of a new group of carbenicillinases. Antimicrob. Agents Chemother. 44, 1070-1074. doi: 10.1128/aac.44.4.1070-1074.2000

Cicek, A. C., Duzgun, A. O., Saral, A., and Sandalli, C. (2014). Determination of a novel integron-located variant (blaOXA -320) of class D $\beta$-lactamase in Proteus mirabilis: a novel integron-located blaOXA- 320 in Proteus mirabilis. J. Basic Microbiol. 54, 1030-1035. doi: 10.1002/jobm.201300264

Cuzon, G., Naas, T., Villegas, M.-V., Correa, A., Quinn, J. P., and Nordmann, P. (2011). Wide dissemination of Pseudomonas aeruginosa producing betalactamase blaKPC-2 gene in Colombia. Antimicrob. Agents Chemother. 55, 5350-5353. doi: 10.1128/AAC.00297-11

Dahmen, S., Madec, J.-Y., and Haenni, M. (2013). F2:A-:B- plasmid carrying the extended-spectrum $\beta$-lactamase blaCTX-M-55/57 gene in Proteus mirabilis isolated from a primate. Int. J. Antimicrob. Agents 41, 594-595. doi: 10.1016/j. ijantimicag.2013.02.004

D’Andrea, M. M., Literacka, E., Zioga, A., Giani, T., Baraniak, A., Fiett, J., et al. (2011). Evolution and spread of a multidrug-resistant Proteus mirabilis clone with chromosomal AmpC-type cephalosporinases in Europe. Antimicrob. Agents Chemother. 55, 2735-2742. doi: 10.1128/AAC.01736-10

D’Andrea, M. M., Nucleo, E., Luzzaro, F., Giani, T., Migliavacca, R., Vailati, F., et al. (2006). CMY-16, a novel acquired AmpC-type beta-lactamase of the CMY/LAT lineage in multifocal monophyletic isolates of Proteus mirabilis from northern Italy. Antimicrob. Agents Chemother. 50, 618-624. doi: 10.1128/aac.50.2.618624.2006

Datta, P., Gupta, V., Arora, S., Garg, S., and Chander, J. (2014). Epidemiology of extended-spectrum $\beta$-Lactamase, AmpC, and carbapenemase production in Proteus mirabilis. Jpn. J. Infect. Dis. 67, 44-46. doi: 10.7883/yoken.67.44

de Champs, C., Bonnet, R., Sirot, D., Chanal, C., and Sirot, J. (2000). Clinical relevance of Proteus mirabilis in hospital patients: a two year survey. J. Antimicrob. Chemother. 45, 537-539. doi: 10.1093/jac/45.4.537

Decré, D., Verdet, C., Raskine, L., Blanchard, H., Burghoffer, B., Philippon, A., et al. (2002). Characterization of CMY-type beta-lactamases in clinical strains of Proteus mirabilis and Klebsiella pneumoniae isolated in four hospitals in the Paris area. J. Antimicrob. Chemother. 50, 681-688. doi: 10.1093/jac/dkf193

Di Pilato, V., Chiarelli, A., Boinett, C. J., Riccobono, E., Harris, S. R., D’Andrea, M. M., et al. (2016). Complete genome sequence of the first KPC-type carbapenemase-positive Proteus mirabilis strain from a bloodstream infection. Genome Announc. 4:e00607-16. doi: 10.1128/genomeA.00607-16

Dirksen, M. S., Wintermans, R. G., Boerema, J. B., and Gimbrère, J. S. (1986). Imipenem as monotherapy in the treatment of intensive care patients with severe infections. J. Antimicrob. Chemother. 18(Suppl. E), 145-151. doi: 10. 1093/jac/18.supplement_e.145

Dixon, N., Fowler, R. C., Yoshizumi, A., Horiyama, T., Ishii, Y., Harrison, L., et al. (2016). IMP-27, a unique metallo- $\beta$-lactamase identified in geographically distinct isolates of Proteus mirabilis. Antimicrob. Agents Chemother. 60, 64186421. doi: 10.1128/AAC.02945-15

Dortet, L., Girlich, D., Virlouvet, A.-L., Poirel, L., Nordmann, P., Iorga, B. I., et al. (2017). Characterization of BRPMBL, the bleomycin-resistance protein associated with the carbapenemase NDM. Antimicrob. Agents Chemother. 61:e02413-16. doi: 10.1128/AAC.02413-16

Dortet, L., Poirel, L., Al Yaqoubi, F., and Nordmann, P. (2012). NDM-1, OXA48 and OXA-181 carbapenemase-producing Enterobacteriaceae in Sultanate of Oman. Clin. Microbiol. Infect. 18, E144-E148.

Doublet, B., Boyd, D., Mulvey, M. R., and Cloeckaert, A. (2005). The Salmonella genomic island 1 is an integrative mobilizable element. Mol. Microbiol. 55, 1911-1924. doi: 10.1111/j.1365-2958.2005.04520.x

Evans, B. A., and Amyes, S. G. B. (2014). OXA -lactamases. Clin. Microbiol. Rev. 27, 241-263. doi: 10.1128/CMR.00117-13

Fursova, N. K., Astashkin, E. I., Knyazeva, A. I., Kartsev, N. N., Leonova, E. S., Ershova, O. N., et al. (2015). The spread of blaOXA-48 and blaOXA-244 carbapenemase genes among Klebsiella pneumoniae, Proteus mirabilis and
Enterobacter spp. isolated in Moscow, Russia. Ann. Clin. Microbiol. Antimicrob. 14:46.

Gaillot, O., Clément, C., Simonet, M., and Philippon, A. (1997). Novel transferable beta-lactam resistance with cephalosporinase characteristics in Salmonella enteritidis. J. Antimicrob. Chemother. 39, 85-87. doi: 10.1093/jac/39.1.85

Galani, I., Souli, M., Panagea, T., Poulakou, G., Kanellakopoulou, K., and Giamarellou, H. (2012). Prevalence of $16 \mathrm{~S}$ rRNA methylase genes in Enterobacteriaceae isolates from a Greek university hospital. Clin. Microbiol. Infect. 18, E52-E54.

Giammanco, G. M., Grimont, P. A. D., Grimont, F., Lefevre, M., Giammanco, G., and Pignato, S. (2011). Phylogenetic analysis of the genera Proteus, Morganella and Providencia by comparison of $r p o B$ gene sequences of type and clinical strains suggests the reclassification of Proteus myxofaciens in a new genus, Cosenzaea gen. nov., as Cosenzaea myxofaciens comb. nov. Int. J. Syst. Evol. Microbiol. 61, 1638-1644. doi: 10.1099/ijs.0.021964-0

Girlich, D., Bonnin, R. A., Bogaerts, P., De Laveleye, M., Huang, D. T., Dortet, L., et al. (2017). Chromosomal amplification of the blaOXA-58 carbapenemase gene in a Proteus mirabilis clinical isolate. Antimicrob. Agents Chemother. 61:e01697-16.

Girlich, D., Dortet, L., Poirel, L., and Nordmann, P. (2015). Integration of the blaNDM-1 carbapenemase gene into Proteus genomic island 1 (PGI1-PmPEL) in a Proteus mirabilis clinical isolate. J. Antimicrob. Chemother. 70, 98-102. doi: $10.1093 / \mathrm{jac} / \mathrm{dku} 371$

Girlich, D., Karim, A., Spicq, C., and Nordmann, P. (2000a). Plasmid-mediated cephalosporinase ACC-1 in clinical isolates of Proteus mirabilis and Escherichia coli. Eur. J. Clin. Microbiol. Infect. Dis. 19, 893-895. doi: 10.1007/ s100960000386

Girlich, D., Naas, T., Bellais, S., Poirel, L., Karim, A., and Nordmann, P. (2000b). Biochemical-genetic characterization and regulation of expression of an ACC1-like chromosome-borne cephalosporinase from Hafnia alvei. Antimicrob. Agents Chemother. 44, 1470-1478. doi: 10.1128/aac.44.6.1470-1478.2000

Gonzalez Leiza, M., Perez-Diaz, J. C., Ayala, J., Casellas, J. M., Martinez-Beltran, J., Bush, K., et al. (1994). Gene sequence and biochemical characterization of FOX-1 from Klebsiella pneumoniae, a new AmpC-type plasmid-mediated beta-lactamase with two molecular variants. Antimicrob. Agents Chemother. 38, 2150-2157. doi: 10.1128/aac.38.9.2150

Guillard, T., Grillon, A., de Champs, C., Cartier, C., Madoux, J., Berçot, B., et al. (2014). Mobile insertion cassette elements found in small non-transmissible plasmids in Proteeae may explain $q n r D$ mobilization. PLoS One 9:e87801. doi: 10.1371/journal.pone.0087801

Hall, R. M., and Collis, C. M. (1995). Mobile gene cassettes and integrons: capture and spread of genes by site-specific recombination. Mol. Microbiol. 15, 593-600. doi: 10.1111/j.1365-2958.1995.tb02368.x

Harada, S., Ishii, Y., Saga, T., Kouyama, Y., Tateda, K., and Yamaguchi, K. (2012). Chromosomal integration and location on IncT plasmids of the blaCTX-M2 gene in Proteus mirabilis clinical isolates. Antimicrob. Agents Chemother. 56, 1093-1096. doi: 10.1128/AAC.00258-11

Harada, S., Ishii, Y., Saga, T., Tateda, K., and Yamaguchi, K. (2010). Chromosomally encoded blaCMY-2 located on a novel SXT/R391-related integrating conjugative element in a Proteus mirabilis clinical isolate. Antimicrob. Agents Chemother. 54, 3545-3550. doi: 10.1128/AAC.00111-10

Helmy, M. M., and Wasfi, R. (2014). Phenotypic and molecular characterization of plasmid mediated AmpC $\beta$-lactamases among Escherichia coli, Klebsiella spp., and Proteus mirabilis isolated from urinary tract infections in Egyptian hospitals. Biomed Res. Int. 2014:171548. doi: 10.1155/2014/171548

Ho, P. L., Ho, A. Y. M., Chow, K. H., Wong, R. C. W., Duan, R. S, Ho, W. L., et al. (2005). Occurrence and molecular analysis of extendedspectrum $\beta$-lactamase-producing Proteus mirabilis in Hong Kong, 1999-2002. J. Antimicrob. Chemother. 55, 840-845. doi: 10.1093/jac/dki135

Hu, Y., Cai, J., Zhang, R., Zhou, H., Sun, Q., and Chen, G. (2012). Emergence of Proteus mirabilis harboring blaKPC-2 and $q n r D$ in a Chinese hospital. Antimicrob. Agents Chemother. 56, 2278-2282. doi: 10.1128/AAC.05519-11

Huang, C.-W., Chien, J.-H., Peng, R.-Y., Tsai, D.-J., Li, M.-H., Lee, H.-M., et al. (2015). Molecular epidemiology of CTX-M-type extended-spectrum $\beta$ lactamase-producing Proteus mirabilis isolates in Taiwan. Int. J. Antimicrob. Agents 45, 84-85. doi: 10.1016/j.ijantimicag.2014.09.004

Jacoby, G. A. (2009). AmpC beta-lactamases. Clin. Microbiol. Rev. 22, 161-182, Tableof Contents. doi: 10.1128/CMR.00036-08 
Jayol, A., Janvier, F., Guillard, T., Chau, F., Mérens, A., Robert, J., et al. (2016). qnrA6 genetic environment and quinolone resistance conferred on Proteus mirabilis. J. Antimicrob. Chemother. 71, 903-908. doi: 10.1093/jac/dkv431

Jones, C. H., Tuckman, M., Keeney, D., Ruzin, A., and Bradford, P. A. (2009). Characterization and sequence analysis of extended-spectrum- $\beta$-lactamaseencoding genes from Escherichia coli, Klebsiella pneumoniae, and Proteus mirabilis isolates collected during tigecycline phase 3 clinical trials. Antimicrob. Agents Chemother. 53, 465-475. doi: 10.1128/AAC.00883-08

Karim, A., Poirel, L., Nagarajan, S., and Nordmann, P. (2001). Plasmid-mediated extended-spectrum beta-lactamase (CTX-M-3 like) from India and gene association with insertion sequence ISEcP1. FEMS Microbiol. Lett. 201, 237-241. doi: 10.1016/s0378-1097(01)00276-2

Kim, J.-Y., Park, Y.-J., Kim, S.-I., Kang, M. W., Lee, S.-O., and Lee, K.-Y. (2004). Nosocomial outbreak by Proteus mirabilis producing extended-spectrum betalactamase VEB-1 in a Korean university hospital. J. Antimicrob. Chemother. 54, 1144-1147. doi: 10.1093/jac/dkh486

Knothe, H., Shah, P., Krcmery, V., Antal, M., and Mitsuhashi, S. (1983). Transferable resistance to cefotaxime, cefoxitin, cefamandole and cefuroxime in clinical isolates of Klebsiella pneumoniae and Serratia marcescens. Infection 11, 315-317. doi: 10.1007/bf01641355

La, M.-V., Jureen, R., Lin, R. T. P., and Teo, J. W. P. (2014). Unusual detection of an Acinetobacter class D carbapenemase gene, blaOXA-23, in a clinical Escherichia coli isolate. J. Clin. Microbiol. 52, 3822-3823.

Labia, R., Guionie, M., and Barthélémy, M. (1981). Properties of three carbenicillin-hydrolysing beta-lactamases (CARB) from Pseudomonas aeruginosa: identification of a new enzyme. J. Antimicrob. Chemother. 7, 49-56. doi: 10.1093/jac/7.1.49

Lartigue, M.-F., Fortineau, N., and Nordmann, P. (2005). Spread of novel expanded-spectrum beta-lactamases in Enterobacteriaceae in a university hospital in the Paris area, France. Clin. Microbiol. Infect. 11, 588-591. doi: 10.1111/j.1469-0691.2005.01172.x

Lauretti, L., Riccio, M. L., Mazzariol, A., Cornaglia, G., Amicosante, G., Fontana, R., et al. (1999). Cloning and characterization of blaVIM, a new integron-borne metallo-beta-lactamase gene from a Pseudomonas aeruginosa clinical isolate. Antimicrob. Agents Chemother. 43, 1584-1590. doi: 10.1128/aac.43.7.1584

Leulmi, Z., Kandouli, C., Mihoubi, I., Benlabed, K., Lezzar, A., and Rolain, J.-M. (2019). First report of blaOXA-24 carbapenemase gene, armA methyltransferase and $a a c\left(6^{\prime}\right)-I b-c r$ among multidrug-resistant clinical isolates of Proteus mirabilis in Algeria. J. Glob. Antimicrob. Resist. 16, 125-129. doi: 10.1016/j.jgar.2018.08.019

Li, X., Du, Y., Du, P., Dai, H., Fang, Y., Li, Z., et al. (2016). SXT/R391 integrative and conjugative elements in Proteus species reveal abundant genetic diversity and multidrug resistance. Sci. Rep. 6:37372. doi: 10.1038/srep37372

Literacka, E., Empel, J., Baraniak, A., Sadowy, E., Hryniewicz, W., and Gniadkowski, M. (2004). Four variants of the Citrobacter freundii AmpCtype cephalosporinases, including novel enzymes CMY-14 and CMY-15, in a Proteus mirabilis clone widespread in Poland. Antimicrob. Agents Chemother. 48, 4136-4143. doi: 10.1128/aac.48.11.4136-4143.2004

Liu, Z., Li, W., Wang, J., Pan, J., Sun, S., Yu, Y., et al. (2013). Identification and characterization of the first Escherichia coli strain carrying NDM-1 gene in China. PLoS One 8:e66666. doi: 10.1371/journal.pone.0066666

Luzzaro, F., Perilli, M., Amicosante, G., Lombardi, G., Belloni, R., Zollo, A., et al. (2001). Properties of multidrug-resistant, ESBL-producing Proteus mirabilis isolates and possible role of beta-lactam/beta-lactamase inhibitor combinations. Int. J. Antimicrob. Agents 17, 131-135. doi: 10.1016/s0924-8579(00)00325-3

Mahillon, J., and Chandler, M. (1998). Insertion sequences. Microbiol. Mol. Biol. Rev. 62, 725-774.

Manoharan, A., Sugumar, M., Kumar, A., Jose, H., Mathai, D., Khilnani, G. C., et al. (2012). Phenotypic \& molecular characterization of AmpC $\beta$-lactamases among Escherichia coli, Klebsiella spp. \& Enterobacter spp. from five Indian medical centers. Indian J. Med. Res. 135, 359-364.

Mariotte, S., Nordmann, P., and Nicolas, M. H. (1994). Extended-spectrum betalactamase in Proteus mirabilis. J. Antimicrob. Chemother. 33, 925-935. doi: 10.1093/jac/33.5.925

Markovska, R., Schneider, I., Keuleyan, E., Ivanova, D., Lesseva, M., Stoeva, T., et al. (2017). Dissemination of a multidrug-resistant VIM-1- and CMY-99producing Proteus mirabilis clone in Bulgaria. Microb. Drug Resist. 23, 345-350. doi: $10.1089 / \mathrm{mdr} .2016 .0026$
Mata, C., Miró, E., Rivera, A., Mirelis, B., Coll, P., and Navarro, F. (2010). Prevalence of acquired AmpC beta-lactamases in Enterobacteriaceae lacking inducible chromosomal ampC genes at a Spanish hospital from 1999 to 2007. Clin. Microbiol. Infect. 16, 472-476. doi: 10.1111/j.1469-0691.2009.02864.x

Mata, C., Navarro, F., Miró, E., Walsh, T. R., Mirelis, B., and Toleman, M. (2011). Prevalence of SXT/R391-like integrative and conjugative elements carrying blaCMY-2 in Proteus mirabilis. J. Antimicrob. Chemother. 66, 2266-2270. doi: $10.1093 / \mathrm{jac} / \mathrm{dkr} 286$

Matsumoto, Y., Ikeda, F., Kamimura, T., Yokota, Y., and Mine, Y. (1988). Novel plasmid-mediated beta-lactamase from Escherichia coli that inactivates oxyimino-cephalosporins. Antimicrob. Agents Chemother. 32, 1243-1246. doi: 10.1128/aac.32.8.1243

Mazzariol, A., Kocsis, B., Koncan, R., Kocsis, E., Lanzafame, P., and Cornaglia, G. (2012). Description and plasmid characterization of qnrD determinants in Proteus mirabilis and Morganella morganii. Clin. Microbiol. Infect. 18, E46-E48. doi: 10.1111/j.1469-0691.2011.03728.x

Mendes, R. E., Castanheira, M., Woosley, L. N., Stone, G. G., Bradford, P. A., and Flamm, R. K. (2019). Characterization of $\beta$-lactamase content of ceftazidimeresistant pathogens recovered during the pathogen-directed phase 3 REPRISE Trial for ceftazidime-avibactam: correlation of efficacy against $\beta$-lactamase producers. Antimicrob. Agents Chemother. 63:e2655-18. doi: 10.1128/AAC. 02655-18

Mitsuyama, J., Hiruma, R., Yamaguchi, A., and Sawai, T. (1987). Identification of porins in outer membrane of Proteus, Morganella, and Providencia spp. and their role in outer membrane permeation of beta-lactams. Antimicrob. Agents Chemother. 31, 379-384. doi: 10.1128/aac.31.3.379

Mojica, M. F., Bonomo, R. A., and Fast, W. (2016). B1-metallo- $\beta$-lactamases: where do we stand? Curr. Drug Targets 17, 1029-1050. doi: 10.2174/ 1389450116666151001105622

Mokracka, J., Gruszczyńska, B., and Kaznowski, A. (2012). Integrons, $\beta$-lactamase and $q n r$ genes in multidrug resistant clinical isolates of Proteus mirabilis and P. vulgaris. APMIS 120, 950-958. doi: 10.1111/j.1600-0463.2012.02923.x

Moland, E. S., Hanson, N. D., Black, J. A., Hossain, A., Song, W., and Thomson, K. S. (2006). Prevalence of newer $\beta$-lactamases in Gram-negative clinical isolates collected in the United States from 2001 to 2002. J. Clin. Microbiol. 44, 33183324. doi: $10.1128 / \mathrm{jcm} .00756-06$

Mollenkopf, D. F., Stull, J. W., Mathys, D. A., Bowman, A. S., Feicht, S. M., Grooters, S. V., et al. (2017). Carbapenemase-producing Enterobacteriaceae recovered from the environment of a swine farrow-to-finish operation in the United States. Antimicrob. Agents Chemother. 61:e01298-16. doi: 10.1128/AAC. 01298- 16

Mugnier, P. D., Poirel, L., Naas, T., and Nordmann, P. (2010). Worldwide dissemination of the blaOXA-23 carbapenemase gene of Acinetobacter baumannii. Emerg. Infect. Dis. 16, 35-40. doi: 10.3201/eid1601.090852

Naas, T., Benaoudia, F., Massuard, S., and Nordmann, P. (2000). Integron-located VEB-1 extended-spectrum beta-lactamase gene in a Proteus mirabilis clinical isolate from Vietnam. J. Antimicrob. Chemother. 46, 703-711. doi: 10.1093/jac/ 46.5.703

Naas, T., Cuzon, G., Villegas, M.-V., Lartigue, M.-F., Quinn, J. P., and Nordmann, P. (2008). Genetic structures at the origin of acquisition of the beta-lactamase blaKPC gene. Antimicrob. Agents Chemother. 52, 1257-1263. doi: 10.1128/AAC. 01451-07

Naas, T., Oueslati, S., Bonnin, R. A., Dabos, M. L., Zavala, A., Dortet, L., et al. (2017). Beta-lactamase database (BLDB) - structure and function. J. Enzyme Inhib. Med. Chem. 32, 917-919. doi: 10.1080/14756366.2017.1344235

Naas, T., Zerbib, M., Girlich, D., and Nordmann, P. (2003). Integration of a transposon Tn1-encoded inhibitor-resistant beta-lactamase gene, blaTEM-67 from Proteus mirabilis, into the Escherichia coli chromosome. Antimicrob. Agents Chemother. 47, 19-26. doi: 10.1128/aac.47.1.19-26.2003

Nagano, N., Shibata, N., Saitou, Y., Nagano, Y., and Arakawa, Y. (2003). Nosocomial outbreak of infections by Proteus mirabilis that produces extendedspectrum CTX-M-2 type beta-lactamase. J. Clin. Microbiol. 41, 5530-5536. doi: $10.1128 /$ jcm.41.12.5530-5536.2003

Nakama, R., Shingaki, A., Miyazato, H., Higa, R., Nagamoto, C., Hamamoto, K., et al. (2016). Current status of extended spectrum $\beta$-lactamase-producing Escherichia coli, Klebsiella pneumoniae and Proteus mirabilis in Okinawa prefecture, Japan. J. Infect. Chemother. 22, 281-286. doi: 10.1016/j.jiac.2016. 01.008 
Nakano, R., Nakano, A., Abe, M., Inoue, M., and Okamoto, R. (2012). Regional outbreak of CTX-M-2 $\beta$-lactamase-producing Proteus mirabilis in Japan. J. Med. Microbiol. 61, 1727-1735. doi: 10.1099/jmm.0.049726-0

Neuwirth, C., Siébor, E., Duez, J. M., Péchinot, A., and Kazmierczak, A. (1995). Imipenem resistance in clinical isolates of Proteus mirabilis associated with alterations in penicillin-binding proteins. J. Antimicrob. Chemother. 36, 335342. doi: $10.1093 / \mathrm{jac} / 36.2 .335$

Nijssen, S., Florijn, A., Bonten, M. J. M., Schmitz, F. J., Verhoef, J., and Fluit, A. C. (2004). Beta-lactam susceptibilities and prevalence of ESBL-producing isolates among more than 5000 European Enterobacteriaceae isolates. Int. J. Antimicrob. Agents 24, 585-591. doi: 10.1016/j.ijantimicag.2004.08.008

Nishio, H., Komatsu, M., Shibata, N., Shimakawa, K., Sueyoshi, N., Ura, T., et al. (2004). Metallo- $\beta$-lactamase-producing Gram-negative bacilli: laboratorybased surveillance in cooperation with 13 clinical laboratories in the Kinki region of Japan. J. Clin. Microbiol. 42, 5256-5263. doi: 10.1128/jcm.42.11.52565263.2004

Nordmann, P., and Naas, T. (1994). Sequence analysis of PER-1 extended-spectrum beta-lactamase from Pseudomonas aeruginosa and comparison with class A beta-lactamases. Antimicrob. Agents Chemother. 38, 104-114. doi: 10.1128/aac. 38.1.104

Ogbolu, D. O., Daini, O. A., Ogunledun, A., Alli, A. O., and Webber, M. A. (2011). High levels of multidrug resistance in clinical isolates of Gram-negative pathogens from Nigeria. Int. J. Antimicrob. Agents 37, 62-66. doi: 10.1016/j. ijantimicag.2010.08.019

O'Hara, C. M., Brenner, F. W., and Miller, J. M. (2000). Classification, identification, and clinical significance of Proteus, Providencia, and Morganella. Clin. Microbiol. Rev. 13, 534-546.

Ohno, Y., Nakamura, A., Hashimoto, E., Matsutani, H., Abe, N., Fukuda, S., et al. (2017). Molecular epidemiology of carbapenemase-producing Enterobacteriaceae in a primary care hospital in Japan, 2010-2013. J. Infect. Chemother. 23, 224-229. doi: 10.1016/j.jiac.2016.12.013

Osano, E., Arakawa, Y., Wacharotayankun, R., Ohta, M., Horii, T., Ito, H., et al. (1994). Molecular characterization of an enterobacterial metallo betalactamase found in a clinical isolate of Serratia marcescens that shows imipenem resistance. Antimicrob. Agents Chemother. 38, 71-78. doi: 10.1128/aac.38.1.71

Österblad, M., Karah, N., Halkilahti, J., Sarkkinen, H., Uhlin, B. E., and Jalava, J. (2016). Rare detection of the Acinetobacter class D carbapenemase blaOXA-23 gene in Proteus mirabilis. Antimicrob. Agents Chemother. 60, 3243-3245.

Pagani, L., Dell'Amico, E., Migliavacca, R., D’Andrea, M. M., Giacobone, E., Amicosante, G., et al. (2003). Multiple CTX-M-type extended-spectrum betalactamases in nosocomial isolates of Enterobacteriaceae from a hospital in northern Italy. J. Clin. Microbiol. 41, 4264-4269. doi: 10.1128/jcm.41.9.42644269.2003

Papagiannitsis, C. C., Miriagou, V., Kotsakis, S. D., Tzelepi, E., Vatopoulos, A. C., Petinaki, E., et al. (2012). Characterization of a transmissible plasmid encoding VEB-1 and VIM-1 in Proteus mirabilis. Antimicrob. Agents Chemother. 56, 4024-4025. doi: 10.1128/aac.00470-12

Papp-Wallace, K. M., Mallo, S., Bethel, C. R., Taracila, M. A., Hujer, A. M., Fernández, A., et al. (2014). A kinetic analysis of the inhibition of FOX-4 $\beta$-lactamase, a plasmid-mediated AmpC cephalosporinase, by monocyclic $\beta$ lactams and carbapenems. J. Antimicrob. Chemother. 69, 682-690. doi: 10.1093/ jac/dkt434

Partridge, S. R., Tsafnat, G., Coiera, E., and Iredell, J. R. (2009). Gene cassettes and cassette arrays in mobile resistance integrons. FEMS Microbiol. Rev. 33, 757-784. doi: 10.1111/j.1574-6976.2009.00175.x

Paton, R., Miles, R. S., Hood, J., Amyes, S. G., Miles, R. S., and Amyes, S. G. (1993). ARI 1: beta-lactamase-mediated imipenem resistance in Acinetobacter baumannii. Int. J. Antimicrob. Agents 2, 81-87. doi: 10.1016/0924-8579(93) 90045-7

Pavez, M., Troncoso, C., Osses, I., Salazar, R., Illesca, V., Reydet, P., et al. (2019). High prevalence of CTX-M-1 group in ESBL-producing Enterobacteriaceae infection in intensive care units in southern Chile. Braz. J. Infect. Dis. 23, 102-110. doi: 10.1016/j.bjid.2019.03.002

Perilli, M., Dell'Amico, E., Segatore, B., de Massis, M. R., Bianchi, C., Luzzaro, F., et al. (2002). Molecular characterization of extended-spectrum $\beta$-lactamases produced by nosocomial isolates of Enterobacteriaceae from an Italian nationwide survey. J. Clin. Microbiol. 40, 611-614. doi: 10.1128/jcm.40.2.611614.2002
Pfeifer, Y., Trifonova, A., Pietsch, M., Brunner, M., Todorova, I., Gergova, I., et al. (2017). Clonal transmission of Gram-negative bacteria with carbapenemases NDM-1, VIM-1, and OXA-23/72 in a Bulgarian hospital. Microb. Drug Resist. 23, 301-307. doi: 10.1089/mdr.2016.0059

Philippon, A., Slama, P., Dény, P., and Labia, R. (2016). A structure based classification of class A $\beta$-lactamases, a broadly diverse family of enzymes. Clin. Microbiol. Rev. 29, 29-57. doi: 10.1128/cmr.00019-15

Poirel, L., Bonnin, R. A., and Nordmann, P. (2012). Genetic features of the widespread plasmid coding for the carbapenemase OXA-48. Antimicrob. Agents Chemother. 56, 559-562. doi: 10.1128/AAC.05289-11

Poirel, L., Dortet, L., Bernabeu, S., and Nordmann, P. (2011). Genetic features of blaNDM-1-positive Enterobacteriaceae. Antimicrob. Agents Chemother. 55, 5403-5407. doi: 10.1128/AAC.00585- 11

Poirel, L., Figueiredo, S., Cattoir, V., Carattoli, A., and Nordmann, P. (2008). Acinetobacter radioresistens as a silent source of carbapenem resistance for Acinetobacter spp. Antimicrob. Agents Chemother. 52, 1252-1256. doi: 10.1128/ AAC.01304-07

Poirel, L., Héritier, C., Tolün, V., and Nordmann, P. (2004). Emergence of oxacillinase-mediated resistance to imipenem in Klebsiella pneumoniae. Antimicrob. Agents Chemother. 48, 15-22. doi: 10.1128/aac.48.1.15-22. 2004

Poirel, L., Naas, T., Guibert, M., Chaibi, E. B., Labia, R., and Nordmann, P. (1999). Molecular and biochemical characterization of VEB-1, a novel class A extended-spectrum beta-lactamase encoded by an Escherichia coli integron gene. Antimicrob. Agents Chemother. 43, 573-581. doi: 10.1128/aac.43.3.573

Poirel, L., Rodriguez-Martinez, J.-M., Mammeri, H., Liard, A., and Nordmann, P. (2005). Origin of plasmid-mediated quinolone resistance determinant QnrA. Antimicrob. Agents Chemother. 49, 3523-3525. doi: 10.1128/aac.49.8.35233525.2005

Potron, A., Hocquet, D., Triponney, P., Plésiat, P., Bertrand, X., and Valot, B. (2019). Carbapenem-susceptible OXA-23-producing Proteus mirabilis in the French community. Antimicrob. Agents Chemother. 63:e00191-19. doi: 10.1128/ AAC.00191-19

Potron, A., Poirel, L., Elhag, K., Al Yaqoubi, F., and Nordmann, P. (2009). VEB-6 extended-spectrum beta-lactamase-producing Proteus mirabilis from Sultanate of Oman. Int. J. Antimicrob. Agents 34, 493-494. doi: 10.1016/j.ijantimicag. 2009.05.002

Power, P., Di Conza, J., Rodríguez, M. M., Ghiglione, B., Ayala, J. A., Casellas, J. M., et al. (2007). Biochemical characterization of PER-2 and genetic environment of blaPER-2. Antimicrob. Agents Chemother. 51, 2359-2365.

Qin, S., Qi, H., Zhang, Q., Zhao, D., Liu, Z.-Z., Tian, H., et al. (2015). Emergence of extensively drug-resistant Proteus mirabilis harboring a conjugative NDM-1 plasmid and a novel Salmonella genomic island 1 variant, SGI1-Z. Antimicrob. Agents Chemother. 59, 6601-6604. doi: 10.1128/AAC.00292-15

Quinteros, M., Radice, M., Gardella, N., Rodriguez, M. M., Costa, N., Korbenfeld, D., et al. (2003). Extended-spectrum beta-lactamases in Enterobacteriaceae in Buenos Aires, Argentina, public hospitals. Antimicrob. Agents Chemother. 47, 2864-2867. doi: 10.1128/aac.47.9.2864-2867.2003

Raimondi, A., Traverso, A., and Nikaido, H. (1991). Imipenem- and meropenemresistant mutants of Enterobacter cloacae and Proteus rettgeri lack porins. Antimicrob. Agents Chemother. 35, 1174-1180. doi: 10.1128/aac.35.6. 1174

Ramos, A. C., Cayô, R., Carvalhaes, C. G., Jové, T., da Silva, G. P., Sancho, F. M. P., et al. (2017). Dissemination of multidrug-resistant Proteus mirabilis clones carrying a novel integron-borne blaIMP-1 in a tertiary hospital. Antimicrob. Agents Chemother. 62:e01321-17. doi: 10.1128/AAC.01321-17

Rhimi-Mahjoubi, F., Bernier, M., Arlet, G., Jemaa, Z. B., Jouve, P., Hammami, A., et al. (2002). Identification of plasmid-encoded cephalosporinase ACC-1 among various enterobacteria (Klebsiella pneumoniae, Proteus mirabilis, Salmonella) isolated from a Tunisian hospital (Sfax 997-2000). Pathol. Biol. 50, 7-11. doi: 10.1016/s0369-8114(01)00260-7

Robledo, I. E., Aquino, E. E., Santé, M. I., Santana, J. L., Otero, D. M., León, C. F., et al. (2010). Detection of KPC in Acinetobacter spp. in Puerto Rico. Antimicrob. Agents Chemother. 54, 1354-1357. doi: 10.1128/AAC.00899-09

Ryan, M. P., Armshaw, P., O’Halloran, J. A., and Pembroke, J. T. (2017). Analysis and comparative genomics of R997, the first SXT/R391 integrative and conjugative element (ICE) of the Indian sub-continent. Sci. Rep. 7:8562. doi: 10.1038/s41598-017-08735-y 
Sardelić, S., Bedenić, B., Sijak, D., Colinon, C., and Kalenić, S. (2010). Emergence of Proteus mirabilis isolates producing TEM-52 extended-spectrum betalactamases in Croatia. Chemotherapy 56, 208-213. doi: 10.1159/000316332

Saurina, G., Quale, J. M., Manikal, V. M., Oydna, E., and Landman, D. (2000). Antimicrobial resistance in Enterobacteriaceae in Brooklyn, NY: epidemiology and relation to antibiotic usage patterns. J. Antimicrob. Chemother. 45, 895-898. doi: $10.1093 /$ jac/45.6.895

Schaffer, J. N., and Pearson, M. M. (2015). Proteus mirabilis and urinary tract infections. Microbiol. Spectr. 3:10.1128/microbiolspec.UTI-0017-2013.

Schmidt, H., and Hensel, M. (2004). Pathogenicity islands in bacterial pathogenesis. Clin. Microbiol. Rev. 17, 14-56. doi: 10.1128/cmr.17.1.14-56.2004

Schultz, E., Cloeckaert, A., Doublet, B., Madec, J.-Y., and Haenni, M. (2017). Detection of SGI1/PGI1 elements and resistance to extended-spectrum cephalosporins in Proteae of animal origin in France. Front. Microbiol. 8:32. doi: 10.3389/fmicb.2017.00032

Schultz, E., Haenni, M., Mereghetti, L., Siebor, E., Neuwirth, C., Madec, J.-Y., et al. (2015). Survey of multidrug resistance integrative mobilizable elements SGI1 and PGI1 in Proteus mirabilis in humans and dogs in France, 2010-13. J. Antimicrob. Chemother. 70, 2543-2546. doi: 10.1093/jac/dkv154

Seiffert, S. N., Tinguely, R., Lupo, A., Neuwirth, C., Perreten, V., and Endimiani, A. (2013). High prevalence of extended-spectrum-cephalosporin-resistant Enterobacteriaceae in poultry meat in Switzerland: emergence of CMY-2- and VEB-6-possessing Proteus mirabilis. Antimicrob. Agents Chemother. 57, 64066408. doi: 10.1128/aac.01773-13

Shen, P., Wei, Z., Jiang, Y., Du, X., Ji, S., Yu, Y., et al. (2009). Novel genetic environment of the carbapenem-hydrolyzing beta-lactamase KPC-2 among Enterobacteriaceae in China. Antimicrob. Agents Chemother. 53, 4333-4338. doi: 10.1128/AAC.00260-09

Sheng, Z., Li, J., Sheng, G., Sheng, J., and Li, L. (2010). Emergence of Klebsiella pneumoniae carbapenemase-producing Proteus mirabilis in Hangzhou, China. Chin. Med. J. 123, 2568-2570.

Siebor, E., and Neuwirth, C. (2011). The new variant of Salmonella genomic island 1 (SGI1-V) from a Proteus mirabilis French clinical isolate harbours blaVEB-6 and qnrA1 in the multiple antibiotic resistance region. J. Antimicrob. Chemother. 66, 2513-2520. doi: 10.1093/jac/dkr335

Song, W., Kim, J., Bae, I. K., Jeong, S. H., Seo, Y. H., Shin, J. H., et al. (2011). Chromosome-encoded AmpC and CTX-M extended-spectrum $\beta$-lactamases in clinical isolates of Proteus mirabilis from Korea. Antimicrob. Agents Chemother. 55, 1414-1419. doi: 10.1128/AAC.01835-09

Spanu, T., Luzzaro, F., Perilli, M., Amicosante, G., Toniolo, A., Fadda, G., et al. (2002). Occurrence of extended-spectrum beta-lactamases in members of the family Enterobacteriaceae in Italy: implications for resistance to beta-lactams and other antimicrobial drugs. Antimicrob. Agents Chemother. 46, 196-202. doi: 10.1128/aac.46.1.196-202.2002

Stock, I. (2003). Natural antibiotic susceptibility of Proteus spp., with special reference to $P$. mirabilis and P. penneri strains. J. Chemother. 15, 12-26.

Takahashi, I., Tsukamoto, K., Harada, M., and Sawai, T. (1983). Carbenicillinhydrolyzing penicillinases of Proteus mirabilis and the PSE-type penicillinases of Pseudomonas aeruginosa. Microbiol. Immunol. 27, 995-1004. doi: 10.1111/j. 1348-0421.1983.tb02934.x

Tamma, P. D., Sharara, S. L., Pana, Z. D., Amoah, J., Fisher, S. L., Tekle, T., et al. (2019). Molecular epidemiology of ceftriaxone-nonsusceptible Enterobacterales isolates in an academic medical center in the United States. Open Forum Infect. Dis. 6:ofz353.

Thomson, K. S., Weber, D. A., Sanders, C. C., and Sanders, W. E. (1990). Beta-lactamase production in members of the family Enterobacteriaceae and resistance to beta-lactam-enzyme inhibitor combinations. Antimicrob. Agents Chemother. 34, 622-627. doi: 10.1128/aac.34.4.622

Tibbetts, R., Frye, J. G., Marschall, J., Warren, D., and Dunne, W. (2008). Detection of KPC-2 in a clinical isolate of Proteus mirabilis and first reported description of carbapenemase resistance caused by a KPC beta-lactamase in P. mirabilis. J. Clin. Microbiol. 46, 3080-3083. doi: 10.1128/JCM.00979-08

Tonkic, M., Mohar, B., Sisko-Kraljević, K., Mesko-Meglic, K., Goić-Barisić, I., Novak, A., et al. (2010). High prevalence and molecular characterization of extended-spectrum $\beta$-lactamase-producing Proteus mirabilis strains in southern Croatia. J. Med. Microbiol. 59, 1185-1190. doi: 10.1099/jmm.0. 016964-0
Tran, H. H., Ehsani, S., Shibayama, K., Matsui, M., Suzuki, S., Nguyen, M. B., et al. (2015). Common isolation of New Delhi metallo-beta-lactamase 1producing Enterobacteriaceae in a large surgical hospital in Vietnam. Eur. J. Clin. Microbiol. Infect. Dis. 34, 1247-1254. doi: 10.1007/s10096-015-2345-6

Tsai, Y.-L., Wang, M.-C., Hsueh, P.-R., Liu, M.-C., Hu, R.-M., Wu, Y.-J., et al. (2015). Overexpression of an outer membrane protein associated with decreased susceptibility to carbapenems in Proteus mirabilis. PLoS One 10:e0120395. doi: 10.1371/journal.pone.0120395

Tsakris, A., Ikonomidis, A., Poulou, A., Spanakis, N., Pournaras, S., and Markou, F. (2007). Transmission in the community of clonal Proteus mirabilis carrying VIM-1 metallo-beta-lactamase. J. Antimicrob. Chemother. 60, 136-139. doi: $10.1093 / \mathrm{jac} / \mathrm{dkm} 138$

van Dijk, K., Voets, G. M., Scharringa, J., Voskuil, S., Fluit, A. C., Rottier, W. C., et al. (2014). A disc diffusion assay for detection of class A, B and OXA-48 carbapenemases in Enterobacteriaceae using phenyl boronic acid, dipicolinic acid and temocillin. Clin. Microbiol. Infect. 20, 345-349. doi: 10.1111/14690691.12322

Verdet, C., Arlet, G., Barnaud, G., Lagrange, P. H., and Philippon, A. (2000). A novel integron in Salmonella enterica serovar enteritidis, carrying the blaDHA1 gene and its regulator gene ampR, originated from Morganella morganii. Antimicrob. Agents Chemother. 44, 222-225. doi: 10.1128/aac.44.1.222-225. 2000

Verdet, C., Arlet, G., Ben Redjeb, S., Ben Hassen, A., Lagrange, P. H., and Philippon, A. (1998). Characterisation of CMY-4, an AmpC-type plasmid-mediated betalactamase in a Tunisian clinical isolate of Proteus mirabilis. FEMS Microbiol. Lett. 169, 235-240. doi: 10.1016/s0378-1097(98)00491-1

Verdet, C., Gautier, V., Chachaty, E., Ronco, E., Hidri, N., Decré, D., et al. (2009). Genetic context of plasmid-carried blaCMY-2-like genes in Enterobacteriaceae. Antimicrob. Agents Chemother. 53, 4002-4006. doi: 10.1128/AAC.00753-08

Villar, H. (1997). Permeability to carbapenems of Proteus mirabilis mutants selected for resistance to imipenem or other beta-lactams. J. Antimicrob. Chemother. 40, 365-370. doi: 10.1093/jac/40.3.365

Vourli, S., Tsorlini, H., Katsifa, H., Polemis, M., Tzouvelekis, L. S., Kontodimou, A., et al. (2006). Emergence of Proteus mirabilis carrying the bla metallo-betalactamase gene. Clin. Microbiol. Infect. 12, 691-694. doi: 10.1111/j.1469-0691. 2006.01489.x

Wachino, J.-I., Yamane, K., Shibayama, K., Kurokawa, H., Shibata, N., Suzuki, S., et al. (2006). Novel plasmid-mediated 16S rRNA methylase, RmtC, found in a Proteus mirabilis isolate demonstrating extraordinary high-level resistance against various aminoglycosides. Antimicrob. Agents Chemother. 50, 178-184. doi: 10.1128/aac.50.1.178-184.2006

Wang, M., Guo, Q., Xu, X., Wang, X., Ye, X., Wu, S., et al. (2009). New plasmidmediated quinolone resistance gene, $q n r C$, found in a clinical isolate of Proteus mirabilis. Antimicrob. Agents Chemother. 53, 1892-1897. doi: 10.1128/AAC. 01400-08

Watanabe, M., Iyobe, S., Inoue, M., and Mitsuhashi, S. (1991). Transferable imipenem resistance in Pseudomonas aeruginosa. Antimicrob. Agents Chemother. 35, 147-151. doi: 10.1128/aac.35.1.147

Williamson, D. A., Sidjabat, H. E., Freeman, J. T., Roberts, S. A., Silvey, A., Woodhouse, R., et al. (2012). Identification and molecular characterisation of New Delhi metallo- $\beta$-lactamase-1 (NDM-1)- and NDM-6-producing Enterobacteriaceae from New Zealand hospitals. Int. J. Antimicrob. Agents 39, 529-533. doi: 10.1016/j.ijantimicag.2012.02.017

Wolter, D. J., Kurpiel, P. M., Woodford, N., Palepou, M.-F. I., Goering, R. V., and Hanson, N. D. (2009). Phenotypic and enzymatic comparative analysis of the novel KPC variant KPC-5 and its evolutionary variants, KPC-2 and KPC-4. Antimicrob. Agents Chemother. 53, 557-562. doi: 10.1128/AAC.007 34-08

Yan, J.-J., Ko, W.-C., Jung, Y.-C., Chuang, C.-L., and Wu, J.-J. (2002). Emergence of Klebsiella pneumoniae isolates producing inducible DHA-1 beta-lactamase in a university hospital in Taiwan. J. Clin. Microbiol. 40, 3121-3126. doi: $10.1128 / \mathrm{jcm} .40 .9 .3121-3126.2002$

Yigit, H., Queenan, A. M., Anderson, G. J., Domenech-Sanchez, A., Biddle, J. W., Steward, C. D., et al. (2001). Novel carbapenem-hydrolyzing betalactamase, KPC-1, from a carbapenem-resistant strain of Klebsiella pneumoniae. Antimicrob. Agents Chemother. 45, 1151-1161. doi: 10.1128/aac.45.4.11511161.2001 
Yokoyama, K., Doi, Y., Yamane, K., Kurokawa, H., Shibata, N., Shibayama, K., et al. (2003). Acquisition of 16S rRNA methylase gene in Pseudomonas aeruginosa. Lancet 362, 1888-1893. doi: 10.1016/s0140-6736(03)14959-8

Yong, D., Lim, Y., Song, W., Choi, Y. S., Park, D.-Y., Lee, H., et al. (2005). Plasmid-mediated, inducible AmpC beta-lactamase (DHA-1)-producing Enterobacteriaceae at a Korean hospital: wide dissemination in Klebsiella pneumoniae and Klebsiella oxytoca and emergence in Proteus mirabilis. Diagn. Microbiol. Infect. Dis. 53, 65-70. doi: 10.1016/j.diagmicrobio.2005. 03.008

Yong, D., Lim, Y. S., Roh, K. H., Choi, Y. S., Park, D.-Y., Yum, J. H., et al. (2006). The first detection of CTX-M-14 extended-spectrum $\beta$-lactamase among diverse $\beta$-lactamase-producing Proteus mirabilis clinical isolates. Diagn. Microbiol. Infect. Dis. 54, 237-239. doi: 10.1016/j.diagmicrobio.2005.09.013

Yong, D., Toleman, M. A., Giske, C. G., Cho, H. S., Sundman, K., Lee, K., et al. (2009). Characterization of a new metallo-beta-lactamase gene, blaNDM-1, and a novel erythromycin esterase gene carried on a unique genetic structure in Klebsiella pneumoniae sequence type 14 from India. Antimicrob. Agents Chemother. 53, 5046-5054. doi: 10.1128/aac.00774-09

Zabel, M. D., Bunch, P. K., and Clark, D. P. (2000). Regulation of the thdF gene, which is involved in thiophene oxidation by Escherichia coli K-12. Microbios $101,89-103$.
Zhang, F., Xie, L., Wang, X., Han, L., Guo, X., Ni, Y., et al. (2016). Further spread of blaNDM-5 in Enterobacteriaceae via IncX3 plasmids in Shanghai, China. Front. Microbiol. 7:424. doi: 10.3389/fmicb.2016.00424

Zhang, S., Sun, J., Liao, X.-P., Hu, Q.-J., Liu, B.-T., Fang, L.-X., et al. (2013). Prevalence and plasmid characterization of the $q n r D$ determinant in Enterobacteriaceae isolated from animals, retail meat products, and humans. Microb. Drug Resist. 19, 331-335. doi: 10.1089/mdr.2012.0146

Zong, Z., Partridge, S. R., and Iredell, J. R. (2009). A blaVEB-1 variant, blaVEB-6, associated with repeated elements in a complex genetic structure. Antimicrob. Agents Chemother. 53, 1693-1697. doi: 10.1128/AAC.01313-08

Conflict of Interest: The authors declare that the research was conducted in the absence of any commercial or financial relationships that could be construed as a potential conflict of interest.

Copyright (c) 2020 Girlich, Bonnin, Dortet and Naas. This is an open-access article distributed under the terms of the Creative Commons Attribution License (CC BY). The use, distribution or reproduction in other forums is permitted, provided the original author(s) and the copyright owner(s) are credited and that the original publication in this journal is cited, in accordance with accepted academic practice. No use, distribution or reproduction is permitted which does not comply with these terms. 